\title{
Lunar Science: The Apollo Legacy
}

\author{
D. S. Burnett
}

Division of Geological and Planetary Sciences, California Institute of Technology, Pasadena, California 91125

\begin{abstract}
A general review of lunar science is presented, utilizing two themes: a summary of fundamental problems relating to the composition, structure, and history of the moon and a discussion of some surprising, unanticipated results obtained from Apollo lunar science. (1) The moon has a crust of approximately $60-$ $\mathrm{km}$ thickness, probably composed of feldspar-rich rocks. Such rocks are exposed at the surface in the light-colored lunar highlands. Many highlands rocks are complex impact breccias, perhaps produced by large basin-forming impacts. Most highlands rocks have ages of $\sim 3.9 \times 10^{\circ} \mathrm{yr}$; the record of igneous activity at older times is obscured by the intense bombardment. The impact rate decreased sharply at 3.8-3.9 $\times 10^{\circ} \mathrm{yr}$ ago. The impact basins were filled by flows of Fe- and, locally, Ti-rich volcanic rocks creating the dark mare regions and providing the strong visual color contrast of the moon, as viewed from earth. Crustal formation has produced enrichments in many elements, e.g., $\mathrm{Ba}, \mathrm{Sr}$, rare earths, and $\mathrm{U}$, analogous to terrestrial crustal rocks. Compared with these elements, relatively volatile elements like $\mathrm{Na}, \mathrm{K}, \mathrm{Rb}$, and $\mathrm{Pb}$ are highly depleted in the source regions for lunar surface rocks. These source regions were also separated from a metal phase, probably before being incorporated into the moon. The physical properties of the lunar mantle are compatible with mixtures of olvine and pyroxene, although $\mathrm{Ca}$ - and Al-rich compositions cannot be ruled out. Deeper regions, below $\sim 1000 \mathrm{~km}$, are probably partially molten. (2) Lunar rocks cooled in the presence of a magnetic field very much stronger than the one that exists today, owing either to dynamo action in an ancient molten core or to an external magnetization of the moon. Lunar soil properties cannot be explained strictly by broken-up local rocks. Distant impacts throw in exotic material from other parts of the moon. About $1 \%$ of the soil appears to be of meteoritic origin. Vertical mixing by impacts is important; essentially all material sampled from lunar cores shows evidence of surface residence. The surface layers of lunar material exposed to space contain a chemical record of implanted solar material (rare gases, $\mathrm{H}$ ) and constituents of a lunar atmosphere $\left({ }^{40} \mathrm{Ar}, \mathrm{Pb}\right)$. Large isotopic fractionation effects for $\mathrm{O}, \mathrm{Si}, \mathrm{S}$, and $\mathrm{K}$ are present. Physical properties of the surface layers are dominated by radiation damage effects. Lunar rocks have impact craters $(\leq 1 \mathrm{~cm})$ produced by microgram-sized interplanetary particles. The contemporary micrometeorite flux may be much higher than is indicated by the microcrater densities, indicating time variations in the flux. Particle track studies on the returned Surveyor camera filter first showed that the Fe nuclei were preferentially enhanced in solar flares.
\end{abstract}

\section{A. INTRODUCTION}

Any flashback on the scientific accomplishments of the past 4-6 yr in the earth and planetary sciences must include a summary of Apollo lunar science. A priori it was probable that major advances in the understanding of the nature and history of a second planet would be forthcoming once lunar samples were available for laboratory study. This has in fact happened. Because of the vast amount of information available it is impossible for any one person to write a scientific summary of Apollo, even if he has lived through the excitement from the very beginning. Also, no two lunar scientists will probably agree on the relative importance of various discoveries. So with all due respect to my colleagues and without any pretense for completeness I want to reminisce on some of the findings of Apollo lunar science that I have found particularly intriguing. This paper is meant for other earth scientists who have not tried to follow the pace of lunar science.

If in the pre-Surveyor era I had written a realistic list of fundamental lunar problems that might be solved or at least significantly constrained by the opportunity to study lunar

Copyright $(1975$ by the American Geophysical Union. materials in terrestrial laboratories, the list of the important questions might have read as follows:

1. What are the differences in highlands and mare materials? Even to the naked eye the lunar surface is not homogeneous (Figure 1). From telescopic observation it was known that the dark (mare) regions were lower and less densely cratered than the lighter-colored highlands, which have a very high density of craters. The differences in crater density indicated that the mare surfaces were younger. Telescopic observations suggested that the mare were lava flows, but the basic distinction between the mare and the highlands rock types were unknown, except that the distinction was likely to be chemical in nature.

2. What is the composition of the moon as a planet? The nonuniform appearance of the moon suggested that planetary differentiation had occurred. But was this a predominant or a minor effect? Could inferences about the composition of the moon as a whole be drawn from chemical studies of returned samples?

3. Why is the density of the moon low, compared with that of the earth or the other inner planets? The large density contrast between the moon $\left(3.34 \mathrm{~g} / \mathrm{cm}^{3}\right)$ and the earth $(5.52$ $\mathrm{g} / \mathrm{cm}^{3}$ ) can only partially be accounted for by the selfcompressional effects of a comparatively large planet like the 


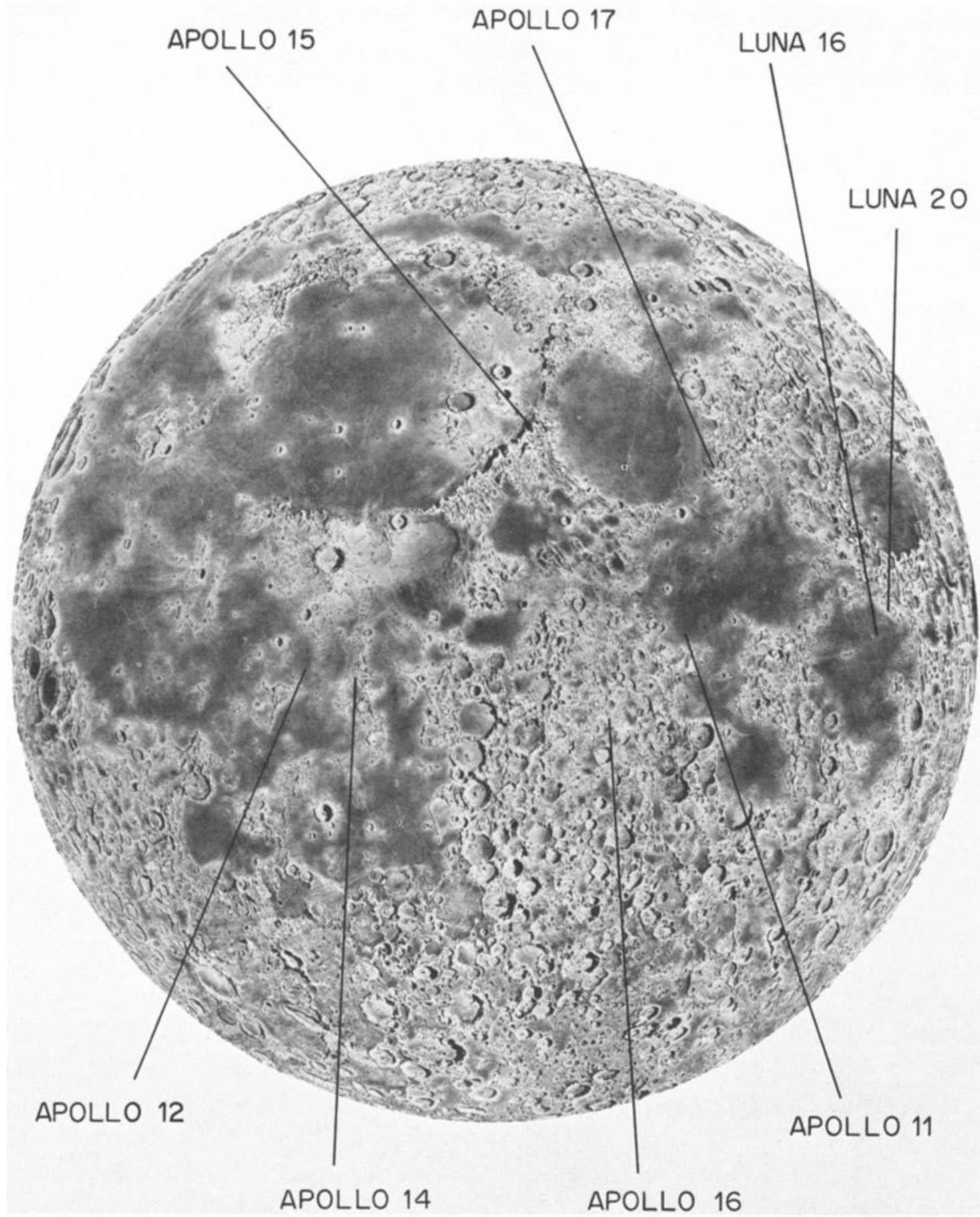

Fig. 1. Sketch of the moon as made by the Czech astronomer Andel in 1926. The Apollo and Luna landing sites are indicated. The dark, sparsely cratered areas (maria) are topographically low in comparison with the light-colored, densely cratered highlands. The Apollo 15 landing site is on the bottom right rim of the large impact basin, Mare Imbrium. Figure courtesy of G. P. Russ.

earth [Kovach and Anderson, 1965]. Moreover, the extreme comparison is between the moon and Mercury, which although its diameter is only 1.4 times the diameter of the moon, has a density of $5.5 \mathrm{~g} / \mathrm{cm}^{3}$. It had been recognized for many years that these density differences must reflect chemical variations, even within the inner solar system, most reasonably reflecting the relative abundance of iron, the most abundant high atomic weight element.

4. What is the internal structure of the moon? The moment of inertia of the moon is consistent with that of a homogeneous planet [Toksöz et al., 1974]. But constrained only by the mass, total density, and moment of inertia, a large degree of internal structure is still permitted.

5. What is the state of evolution of the moon? Thermally, the earth is an active planet. The great majority of the surface and near-surface rocks of the earth have ages that are only a fraction of the age of the planet itself. In contrast, meteorites are primarily debris that has survived intact from the beginning of the solar system. Where does lunar material fit into this hierarchy? 
Fundamental problems always turn out to be difficult; the above list is no exception. Furthermore, it is clear that the above problems cannot be isolated totally and attacked independently; they are strongly intertwined. It was not obvious, pre-Apollo, that any answers to these questions could be obtained, and completely satisfactory solutions on all counts do not exist at present. But is is important to reflect on where things stand and to consider what are the prospects for the future with respect to these major problems. This will be one theme of this paper.

However, there is a second theme that I wish to develop in parallel. The above problems could have been formulated without specific knowledge of lunar materials. In this sense they were 'anticipated' problems to be studied, even though the results obtained were in many ways surprising. However, in any venture into an unexplored research area, one always also hopes to find exciting 'unanticipated' results, and I believe that this was the case with lunar science. Even though it is possible that in some cases the results were unanticipated only by me, I found the following results new and exciting: (1) a highly nonuniform cratering rate in the early history of the moon, (2) impact. breccias as the dominant highlands rock type, (3) a lunar paleomagnetic field, perhaps as large as that of the earth, (4) exotic components in the lunar soils (regolith), (5) fundamentally different properties for lunar surface layers, (6) microcraters on rocks, and (7) an enhanced solar flare iron flux.

For reasons of simplicity, brevity, and personal preference the discussion of the above two lists will focus on general interpretations and conclusions that are relatively 'model independent.' Many models have been formulated to address some of these topics more fully and to provide more specific conclusions than those given below. Such models are vital to lunar science. They are the quantitative manifestations of the qualitative observations that I will discuss. For the most part they are intelligently formulated, plausible, and perhaps in some cases even correct, but given the scope of this article, most discussion of these models will be by reference.

I make no pretense for complete referencing; all references cited are to be interpreted as having the implicit prefix, "see, for example.'

\section{B. Fundamental Lunar Problems}

\section{Mare Versus Highlands Rocks}

The Surveyor missions showed that the lunar maria were composed of volcanic rocks [e.g., Turkevich, 1974], comfirming earlier suggestions made by telescopic observations. Returned materials from Apollo 11 (Mare Tranquillitatis), Apollo 12 (Oceanus Procellarum), Apollo 15 (Mare Imbrium), Apollo 17 (Mare Serenitatis), and Luna 16 (Mare Fecunditatis) (Figure 1) have led to the establishment of a rock type that has become known as 'mare basalt' [Papike et al., 1974; Hays and Walker, 1975]. Figures 2-4 illustrate the distinctive chemical properties of mare basalts, as compared with compositions of highlands rocks and terrestrial basalt. Figure 1 shows that the much-publicized high $\mathrm{Ti}$ contents of mare basalts are confined to samples returned from Apollo 11 and 17. Telescopic observations indicate that these sites are among the darkest of the moon [Head, 1974]. If this correlation is generally valid, rocks of $10-15 \% \mathrm{TiO}_{2}$ are not rare but are probably somewhat atypical of the maria as a whole, although many relatively high $\mathrm{Ti}$ regions were seen by the orbital gamma experiment [Metzger et al., 1974]. The low Ti mare basalts

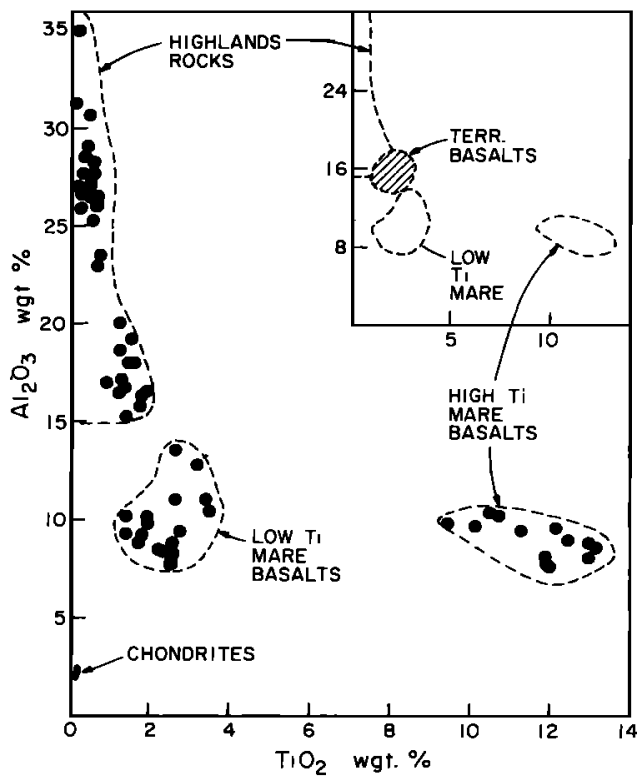

Fig. 2. Correlation diagram of $\mathrm{Al}_{2} \mathrm{O}_{3}$ versus $\mathrm{TiO}_{2}$, showing fields occupied by mare basalts, highlands rocks, and chondrites. No lunar soils have been plotted. The insert compares the lunar fields with the one-standard-deviation spread in the distribution of $\mathrm{Al}_{2} \mathrm{O}_{3}$ and $\mathrm{TiO}_{2}$ analyses for all terrestrial basalts, including both continental and oceanic samples, as compiled by Manson [1967]. The terrestrial range is approximate; any correlation of $\mathrm{Al}_{2} \mathrm{O}_{3}$ and $\mathrm{TiO}_{2}$ has been neglected. The high Ti mare basalts are from Apollo 11 and 17 and differ greatly from any terrestrial counterpart. The low Ti mare basalts are from Apollo 12 and 15. Mare and highlands rocks are clearly distinguished on this plot. Lunar analyses are taken from papers by Rose and his co-workers, Rhodes and his co-workers, and Compston and his co-workers in the Lunar Science Conference proceedings.

are more similar to their terrestrial counterparts; however, essentially no terrestrial basalt is compositionally equivalent to the high $\mathrm{Ti}$ mare basalts. The existence of high Ti basalts is generally attributed to an enrichment in $\mathrm{Ti}$ for the moon as a whole and is paralleled by an analogous enrichment of many other such. 'refractory' elements in lunar materials (see section B2). As Figures 3 and 4 show, mare basalts are also Fe-rich, alkali-poor rocks in comparison with terrestrial basalts. On the other hand, lunar and terrestrial surface rocks, as well as many achondritic meterorites, have much lower $\mathrm{Fe} / \mathrm{Si}$ and $\mathrm{Mg} / \mathrm{Si}$ ratios than chondrites; this can be viewed as a natural consequence of planetary magmatic differentiation processes in an Fe- and Mg-rich solar system.

The high $\mathrm{Fe}$ and $\mathrm{Ti}$ contents in mare basalts are expressed mineralogically as Fe-rich clinopyroxenes plus ilmenite and other Fe-Ti oxides, some previously unknown terrestrially [Haggerty, 1973]. The high abundance of these dark minerals and their relative absence in highland rocks account for the striking visual contrast of the near side of the moon. Although they are far from a homogeneous population, highlands rocks are all characterized by high proportions of Ca-rich plagioclase feldspar, reflected by high $\mathrm{Al}_{2} \mathrm{O}_{3}$ (Figure 1) and low FeO (Figure 3), and are consequently light-colored rocks. The Al-rich, Fe-poor nature of highlands rocks was first established by Surveyor 7 [Patterson et al., 1970]. Anomalous anorthositic fragments in the Apollo 11 soils [Wood et al., 1970], feldspar-rich rocks (including pure anorthosites) from 


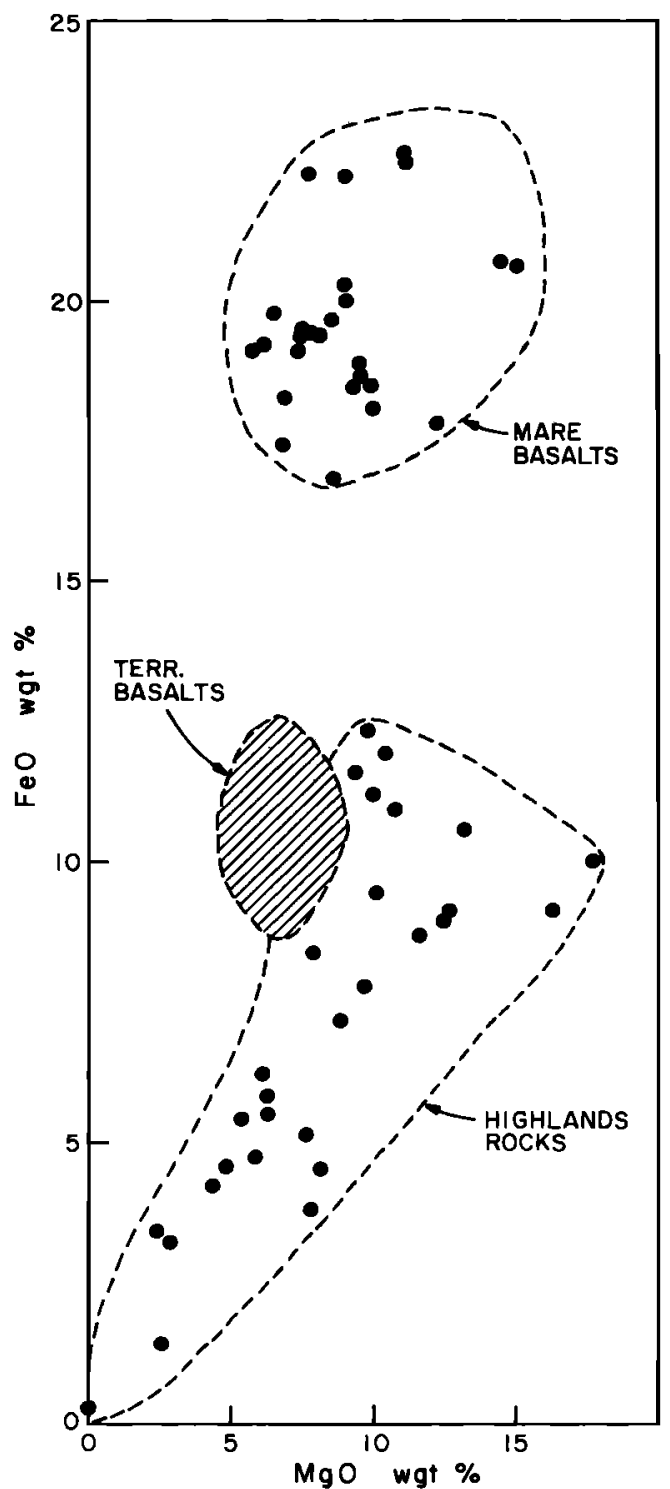

Fig. 3. Correlation diagram of individual analyses of lunar rocks and an approximate field for terrestrial basalts defined by the standard deviation of the distribution of $\mathrm{Fe}$ and $\mathrm{MgO}$ analyses for basalts as compiled by Manson [1967]. Both oceanic and continental samples are represented. Lunar data are from sources given in caption of Figure 2. Mare and highlands rocks are clearly distinguished on the basis of their iron contents.

Apollo 14, Apollo 16, and Luna 20, plus the mountain front areas sampled during Apollo 15 and 17 provide our present sampling of highlands rocks (Figure 1). The overall Al-rich character of the lunar highlands has been established by uniformly high $\mathrm{Al} / \mathrm{Si}$ ratios for all highlands areas observed by the orbital $X$ ray fluorescence experiments on Apollo 15 and 16 [Adler et al., 1973].

As was indicated in the introduction, the high proportion of breccias returned from the highlands sites was a major surprise. Because of analogies to breccias from terrestrial impact craters and because of the domination of lunar surface features by the impact processes these rocks are universally believed to be impact breccias [James, 1975]. Some breccias are very weakly consolidated and contain distinct rock and mineral fragments. In some spectacular examples, e.g., 15465, the frag- ments are cemented together by thick veins of bubbly glass. Other breccias are much more coherent and uniform in appearance, presumably owing to a high degree of postimpact thermal annealing [James, 1975; Phinney et al., 1975]. Many petrologists believe that the bulk of the highlands breccias are the products of very large, possibly basin-forming impact events. A particularly strong case can be made for Apollo 14 breccias [Chao et al., 1972], because the landing site was on a ridge of ejecta extending southward (Figure 1) from the huge Imbrium impact basin. Many petrologists believe that some highlands rocks that show igneous textures (e.g., 68415 and 14310) are derived from impact-produced melts [Phinney et al., 1975].

\section{Chemical Composition of the Moon}

Figures 2-4 show that magmatic and impact processes have produced lunar materials of a wide variety of compositions. Looking through these effects would be impossible with only major element data; however, because of the large body of high-quality trace element and isotopic data on lunar samples, it is possible to make some qualitative inferences about the composition of the moon as a planet.

Lithophile element abundance patterns. Figure 5 shows the concentration ranges observed for six important elements expressed as a ratio of the lunar rock abundance to that for average solar system nonvolatile material. As is customary,

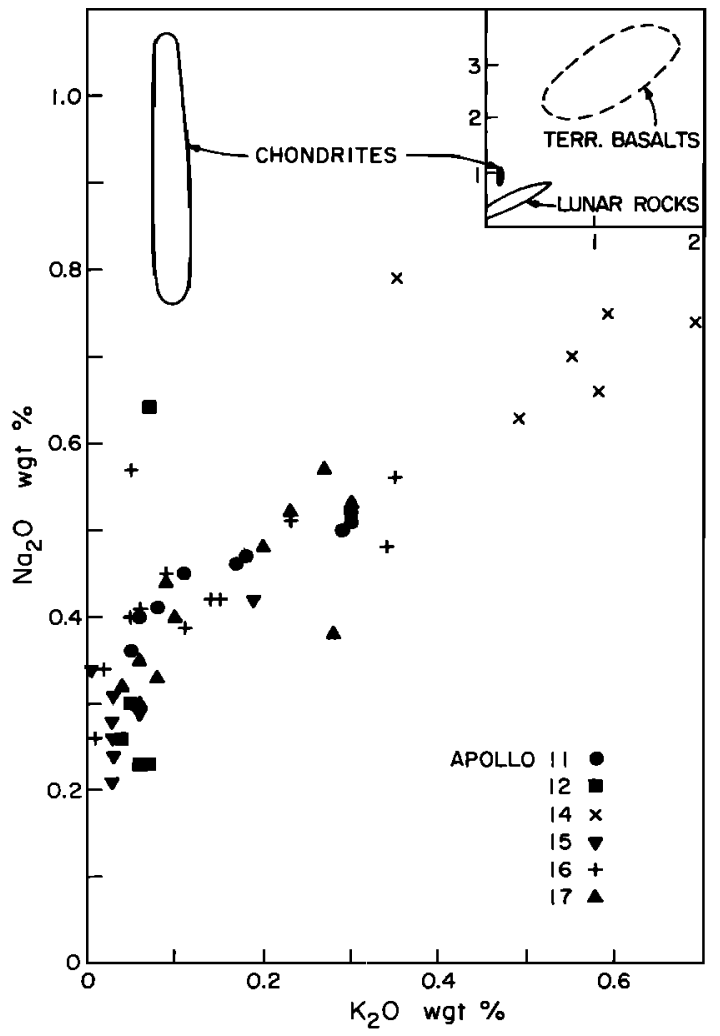

Fig. 4. Correlation diagram of $\mathrm{Na}_{2} \mathrm{O}$ versus $\mathrm{K}_{2} \mathrm{O}$ in lunar rocks (individual data points). The field described by the various chondrite classes is indicated. The insert is the same plot on a larger scale. The area enclosed by the dashed line indicates the average of various terrestrial basalt subtypes as defined by Manson [1967]. The terrestrial field may overrepresent alkali basalt types; nevertheless, the alkalipoor character (particularly for $\mathrm{Na}$ ) of many lunar rocks is shown. The region south of Mare Imbrium is rich in $\mathbf{K}$ as shown by the Apollo 14 rocks. Lunar data are from sources given in caption of Figure 2. 


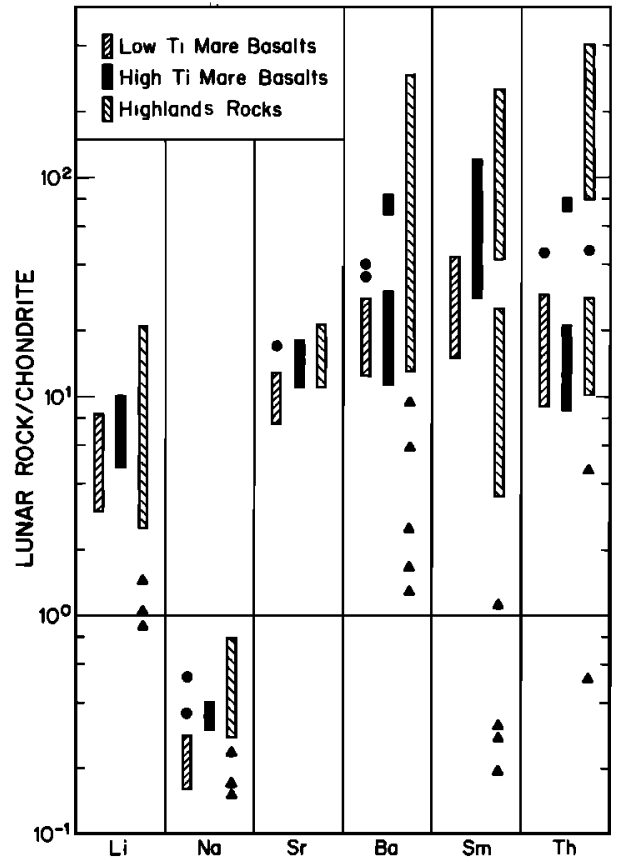

Fig. 5. Abundance patterns of lithophile elements in lunar rocks relative to chondrites. Fields are indicated separately for low $\mathrm{Ti}$ mare basalt (Apollo 12 and 15 and 14053), high Ti mare basalt (Apollo 11 and 17), and 'highlands rocks' (Apollo 14 and 16 plus rocks sampled from mountain front stations on Apollo 15 and 17). Fields are indicated where there appears to be a continuum of data points, but if individual rocks can be plotted as recognizable discrete points, this has been done. Low abundance rocks, designated by triangles, are listed as anorthosites in the original literature sources. The discrete low $\mathrm{Ti}$ mare basalt samples with enhanced abundances are 12038 and 14053 . The Apollo 11 'high $\mathrm{K}$ ' basalts appear as a discrete blob at $\sim 70$ times chondrites for $\mathrm{Ba}$ and $\mathrm{Th}$ for the high $\mathrm{Ti}$ mare basalts. Data were obtained from papers by Philpotts and his co-workers, Gast and Hubbard and their co-workers, and Tatsumoto and his co-workers in the second volume of the various Lunar Science Conference proceedings, as well as from Tatsumoto [1972], Silver [1970], and Tera et al. [1970]. The features of this plot are not sensitive to the class of chondrites used for reference. Chondritic abundances are from Philpotts et al. [1972] plus $9000 \mathrm{ppm}$ for $\mathrm{Na}$ and 46 $\mathrm{ppb}$ for Th.

type 1 carbonaceous chondritic meteorites are adopted as the source of average solar system abundances [Anders, 1971]. Although there is a wide range of measured concentrations for various lunar rocks, all of these elements except $\mathrm{Na}$ are enriched in lunar samples by roughly an order of magnitude. $\mathrm{Na}$ is slightly but consistently depleted, as can also be seen from Figure 4.

There are at least two factors that contribute to the abundance pattern shown on Figure 5 and are also probably responsible for the tendency of lunar rocks to be $\mathrm{Ti}$ rich (Figure 2). These factors are (1) the formation of a lunar crust, presumably by internal differentiation of the moon, and (2) a systematic enhancement in the moon as a whole for those elements that are both refractory (highly nonvolatile) and lithophile, i.e., that show preferential incorporation into silicate phases (as opposed to sulfide or metal).

There is abundant chemical evidence for the existence of a lunar crust qualitatively analogous to the crust of the earth. The elements shown in Figure 5 also tend to be enriched in many terrestrial crustal rocks; however, this is only a suggestive argument. A much stronger argument follows from the $T h$ and $U$ concentrations in lunar samples. If the Th in the moon as a whole were as high $(\sim 0.5 \mathrm{ppm})$ as is measured in most lunar samples, then the moon as a whole would be molten today throughout most of its interior [Toksöz and Solomon, 1973]. This is shown not to be the case by seismic studies (see next section). Further, the lunar heat flow would be much higher than is actually observed [Langseth et al., 1973]. Thus the conclusion is inescapable that $\mathrm{Th}$ and other elements that have similar geochemical behavior have been differentiated upward into a lunar crust. Orbital gamma ray measurements have shown that rocks with $\sim 0.5-\mathrm{ppm} \mathrm{Th}$ are not rare on the lunar surface but that rocks with very high ( $\sim 3.5 \mathrm{ppm}) \mathrm{Th}$ tend to be concentrated on the lunar near side, particularly in the areas south of Mare Imbrium [Metzger et al., 1974]. Many such rocks were sampled by Apollo 14 and account for the highest enrichments $(\sim 100)$ shown on Figure 5 for all elements.

Thus to a first approximation, lunar chemistry is dominated by the crustal formation process, and this process must be dealt with before conclusions can be drawn about the nature of the source materials and the composition of the moon as a whole. The general types of data on which models of lunar magmatic processes can be based are: (1) experimental petrologic studies of the compositions of the liquidus phases for actual and hypothetical lunar bulk compositions [Hays and Walker, 1975] and (2) the relative abundances of trace elements (e.g., rare earths [Haskin et al., 1974; Weill et al., 1974]) or isotopes (e.g., initial ${ }^{87} \mathrm{Sr} /{ }^{88} \mathrm{Sr}$ [Papanastassiou and Wasserburg, 1972a]). The simplest cases to discuss are abundance ratios for elements that appear to be relatively invariant in magmatic processes. An important example is the $\mathrm{K} / \mathrm{U}$ ratio, which as was pointed out by Wasserburg et al. [1964], is remarkably invariant at 1-2 $\times 10^{4}$ for terrestrial igneous rocks and as is illustrated in Figure 6, has a value of $\sim 2 \times 10^{3}$ for lunar rocks with $K$ contents of $0.02-2 \%$. The total range in $\mathrm{K} / \mathrm{U}$ for both the lunar and the terrestrial samples shown is about plus or minus a factor of 2 . Both the lunar and the terrestrial $\mathrm{K} / \mathrm{U}$ ratios are distinctly lower than the ratio for ordinary chondrites, although the terrestrial and carbonaceous chondrite values are not clearly resolved. The correlated enhancement of $K$ and $U$ in the liquid phase until the final stages of crystallization of a mare basalt has been shown by $\mathrm{U}$ microdistribution studies [Burnett et al., 1971b].

The remarkable coherence of $\mathrm{K} / \mathrm{U}$ implies that it can be considered a 'planetary constant' and that in particular, $\mathrm{K} / \mathrm{U}$ $\sim 2 \times 10^{3}$ is a general property of at least lunar crustal rocks and their source regions. Examples of other comparatively invariant lithophile element ratios are $\mathrm{Zr} / \mathrm{Hf}$ [Ehmann and Chyi, 1974], Fe/Mn, K/Ba [Wänke et al., 1973], Th/U [Toksöz and Solomon, 1973], and $\mathrm{Tl} / \mathrm{U}$ [Krähenbühl et al., 1973]. In the absence of the observed uniformity of the relative $\mathrm{K} / \mathrm{U} / \mathrm{Th}$ abundances, calculations of the thermal history of the moon and other planets [Toksöz and Johnston, 1975] would not be meaningful.

The low lunar $\mathrm{K} / \mathrm{U}$ ratio compared with that for chondrites is generally interpreted as reflecting preferential enhancement of refractory elements in the moon and a corresponding depletion in elements that are even moderately volatile, e.g., $\mathrm{K}, \mathrm{Rb}$, and $\mathrm{Cs}$. The volatility of $\mathrm{Na}$ is presumably also the reason for its apparent underabundance compared with the other ele- 


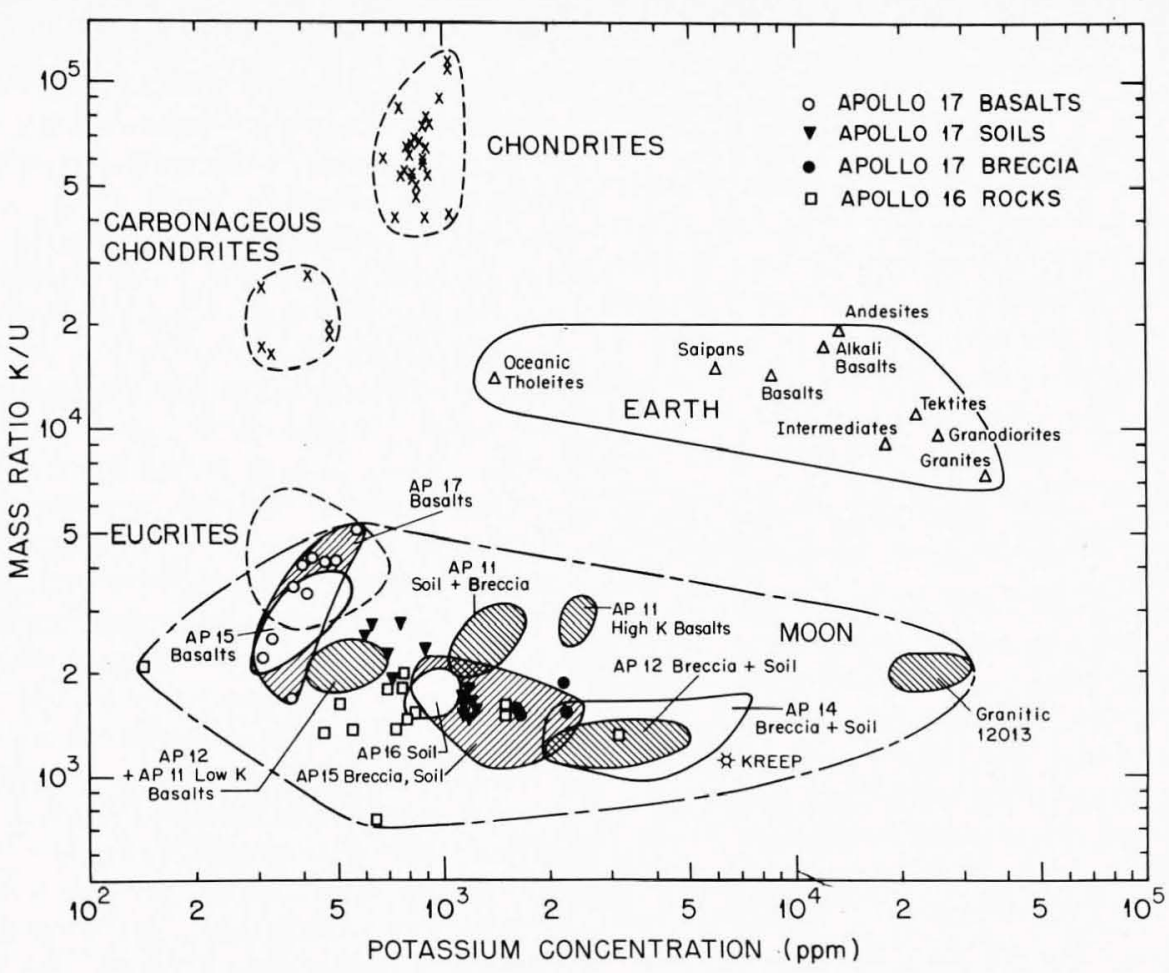

Fig. 6. Comparison of $\mathrm{K} / \mathrm{U}$ ratios and $\mathrm{K}$ concentration for lunar rocks, terres al igneous rocks, chondrites, and eucritic meteorites, as given by Eldridge et al. [1974]. All or these solar system objects have remarkably well defined $\mathrm{K} / \mathrm{U}$ ratios. It appears that this ratio and other lithophile element ratios are approximately preserved in magmatic processes and can be regarded as 'planetary constants.'

ments in Figure 5. $\mathrm{Na}$ is an element that should have been enriched in the formation of a plagioclase-rich crust but that despite crustal enrichment is not even present in average solar system abundance levels.

A direct indication of the chemistry of the source regions of the lunar surface rocks is the initial ${ }^{87} \mathrm{Sr} /{ }^{88} \mathrm{Sr}$ ratio, i.e., the value of this ratio at the time of crystallization [Papanastassiou and Wasserburg, 1972a]. This quantity is very accurately determined and will vary depending on the contribution of ${ }^{87} \mathrm{Sr}$ from the radioactive decay of ${ }^{87} \mathrm{Rb}$ in the source regions of the rocks prior to their formation. In turn, this will depend on the $\mathrm{Rb} / \mathrm{Sr}$ ratio of the source region. A high $\mathrm{Rb} / \mathrm{Sr}$ in the source region will tend to give higher initial ${ }^{87} \mathrm{Sr} /{ }^{86} \mathrm{Sr}$ ratios and vice versa. As is shown in Figure 7, lunar rocks have initial ${ }^{87} \mathrm{Sr} /$ ${ }^{86} \mathrm{Sr}$ ratios that are among the lowest known for any solar system material, even for lunar rocks that formed almost $1.5 \times$ $10^{9} \mathrm{yr}$ after the solar system. The source regions are required to have $\mathrm{Rb} / \mathrm{Sr}$ much less $(\sim 0.005)$ than average solar system values. The separation of $\mathrm{Rb}$ and $\mathrm{Sr}$ and presumably of all other volatile and refractory elements as well must have occurred very early in the history of the solar system, or else initial ${ }^{87} \mathrm{Sr} /{ }^{86} \mathrm{Sr}$ values much higher than those for meteorites would be observed.

Similarly, $\mathrm{Pb}$ isotopic data [Tera et al., 1974b] show that the source regions for lunar rocks are strongly depleted in $\mathrm{Pb}$ (a volatile element) compared to $\mathrm{U}$ and $\mathrm{Th}$ (refractory elements). But, more importantly, the $\mathrm{Pb}$ data also show that lunar rocks formed from parent materials which had $\mathrm{Pb} / \mathrm{U}$ ratios much lower than those for the source regions of terrestrial rocks, conclusively showing a fundamental chemical difference between the earth and the moon.

Volatile element abundance patterns. As was discussed in the preceding section, elements such as $\mathrm{Na}, \mathrm{K}$, and $\mathrm{Rb}$, which are only moderately volatile, appear to be depleted; thus it might be expected that elements that are highly volatile should be highly depleted. Figure 8, based primarily on data from Anders and his co-workers, shows that although volatile elements are depleted overall, there is a surprisingly large range of abundances for these elements in lunar rocks. The halogens

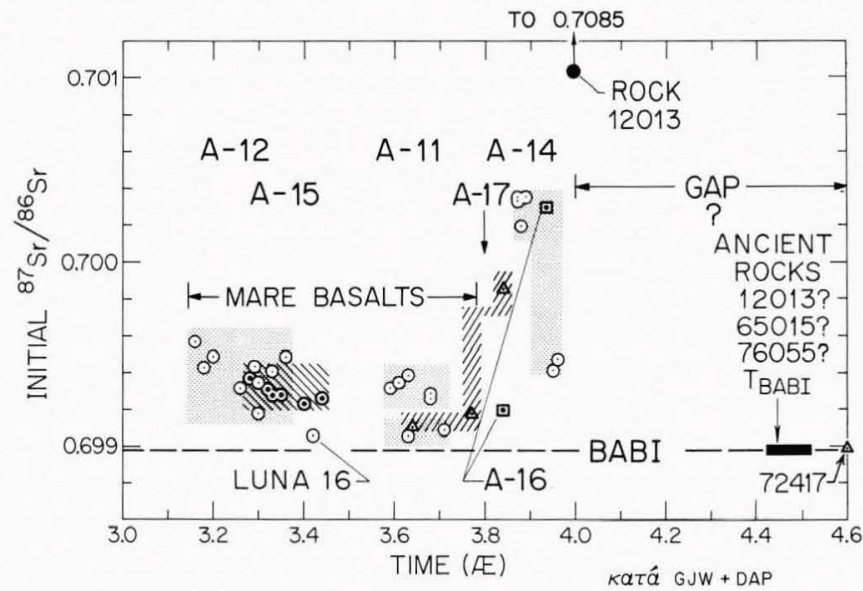

Fig. 7. Comparison of $\mathrm{Rb}-\mathrm{Sr}$ isochron ages (data points) and initial ${ }^{87} \mathrm{Sr} /{ }^{86} \mathrm{Sr}$ ratios for lunar rocks, taken from measurements of Papanastassiou and Wasserburg (A, Apollo mission; BABI, typical primitive ${ }^{87} \mathrm{Sr} /{ }^{86} \mathrm{Sr}$ value that would characterize a solar system object (e.g., meteorite) formed at $\left.4.6 \mathrm{AE}\left(1 \mathrm{AE}=10^{9} \mathrm{yr}\right)\right)$. Although lunar rocks were formed as much as $1.4 \mathrm{AE}$ after the solar system, the initial ${ }^{87} \mathrm{Sr} /$ ${ }^{86} \mathrm{Sr}$ ratios are only slightly above BABI, showing that the source regions for lunar crustal rocks have a very low $\mathrm{Rb} / \mathrm{Sr}$. The age pattern of lunar rocks is very unusual with no rocks younger than $\sim 3.2$ $\mathrm{AE}$ and few rocks with ages between 4.0 and 4.5. The list of ancient rocks indicates samples that may have formed originally at $\sim 4.5$ but were reheated at $\sim 4.0 \mathrm{AE}$. 


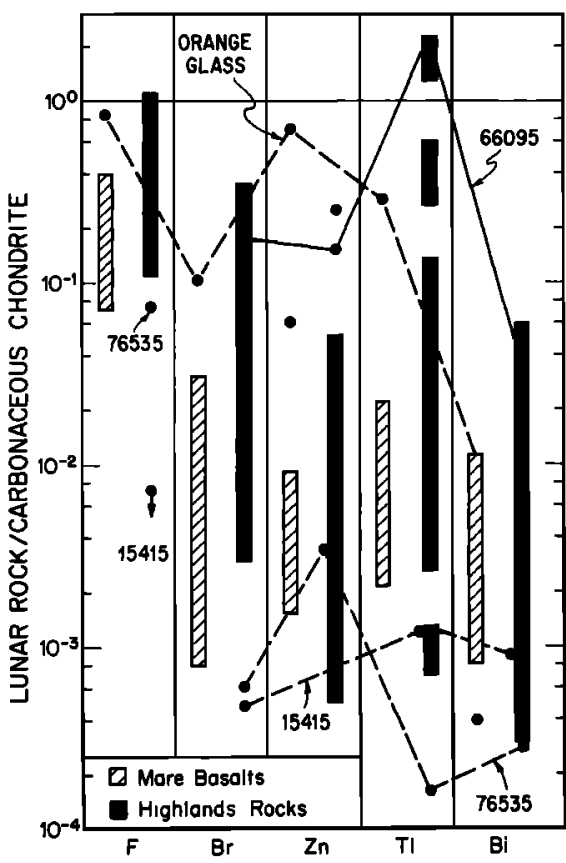

Fig. 8. Volatile element abundance patterns in lunar rocks, expressed as the ratio of the measured concentration in lunar rocks to that of $\mathrm{Cl}$ carbonaceous chondrites. Data for soils and soil breccias are not plotted except for the Apollo 17 orange glass (74220) and the Apollo 15 green glass (15426), which are regarded as igneous glasses and plotted along with mare basalts. Abundances are plotted relative to $\mathrm{Cl}$ carbonaceous chondrites by using reference values from Ganapathy et al. [1970] and $120 \mathrm{ppm}$ for $\mathrm{F}$ [Goldberg et al., 1975]. Data for $F$ are from papers by Reed and his coworkers and by Wänke and his co-workers in the Lunar Science Conference proceedings plus work by Reed and Jovanovic [1973]. Similarly, data for other elements are from work by Anders and his co-workers. Individual analyses or gaps are indicated where there is at least a factor of 2 in abundance compared with the broad continuum of data points. The gaps in the $\mathrm{Tl}$ concentration range are probably not significant, and the $\mathrm{Tl}$ abundance pattern in lunar highlands rocks should be regarded as stretching, essentially continuously, over 4 orders of magnitude. The lines show the patterns for selected individual samples: the 74220 orange glass, the volatile-rich 'rusty rock' (66095), the 15415 anorthosite, and the coarsegrained plagioclase-olivine rock (76535).

$\mathrm{F}$ and $\mathrm{Br}$ were selected as examples of elements whose most distinctive geochemical property is volatility. In addition to being volatile, $\mathrm{Tl}$ behaves as a lithophile element [Krähenbühl et al., 1973] and is known to correlate with alkalis in terrestrial igneous rocks [Ahrens, 1965]. Similarly, $\mathrm{Zn}$ and $\mathrm{Bi}$ are chalcophilic, i.e., tend to concentrate in sulfide minerals. Except for $F$, which appears to behave somewhat independently for reasons that are not clear, these elements show a relatively restricted range of depletions of $10^{-8}-10^{-2}$ in mare basalts but show a wide range of concentrations (spanning 4 orders of magnitude for Tl!) in highlands rocks. A large number of highlands rocks have 10-100 times higher concentrations than mare basalts. However, coarse-grained crystalline highlands rocks, such as the anorthosite rock 15415 or the plagioclaseolivine rock 76535 , have extremely low abundances of volatile elements, as is illustrated specifically in Figure 8 . The rocks (e.g., 66095) showing spectacular Tl enrichments ( 1 on Figure 8), along with distinct enhancements of the other volatile elements (except F), are from the southern part of the Apollo 16 site; however, several different rock types are represented in this population [Krähenbühl et al., 1973; Morgan et al., 1974]. Rock 66095 is the famous 'rusty rock' [Taylor et al., 1973], which attracted attention because of prominent red stains due to the presence of hydrated ferric oxide. The rust and $\mathrm{H}_{2} \mathrm{O}$ appear to be the result of oxidation of $\mathrm{FeCl}_{2}$ in the rock by terrestrial oxygen and water vapor [Taylor et al., 1974; Epstein and Taylor, 1974]; nevertheless, the presence of a mineral like $\mathrm{FeCl}_{2}$ (and $\mathrm{ZnS}$ [El Goresy et al., 1973]) in a lunar rock is of considerable interest. The Tl enrichments appear to be unrelated to the lithophile character of this element [Krähenbühl et al.,1973] and are probably too large to be ascribed to the addition of any known type of meteoritic material, although this may not be true for $\mathrm{Bi}$. Moreover, 66095 contains excess $\mathrm{Pb}$ with a distinctly lunar isotopic composition [Nunes and Tatsumoto, 1973]. At least one of the Tlrich rocks (60025) appears to contain indigenous lunar Xe, which is isotopically identical to the $\mathrm{Xe}$ in the terrestrial atmosphere and distinct from the Xe found in most meteorites or the solar wind [Lightner and Marti, 1974]. This is an additional argument for a lunar origin for the volatiles in the volatile-rich Apollo 16 rocks. Because these rocks are about $3.9 \times 10^{\circ} \mathrm{yr}$ old (section B4), the volatiles must have been incorporated very early in lunar history. Thus these large volatile enrichments must be ascribed to outgassing of at least the outer portions of the moon during crustal formation [Krähenbühl et al., 1973], and rocks like 66095 are probably the closest lunar analogs to the terrestrial oceans and atmosphere. (The ancients had it backwards; the volatiles are in the highlands not in the maria!)

If outgassing has enhanced the abundances of volatile elements in lunar surface rocks, the fact that most rocks still have abundances that are $10^{-3}-10^{-1}$ of carbonaceous chondrites indicates either that the source material was highly depleted in volatile consitutents or that loss mechanisms were very efficient in removing the outgassed volatiles from the moon. For example, ionization and acceleration of an atom by the solar wind can sweep material out of a tenuous lunar atmosphere [Manka and Michel, 1971]. This latter possibility may play some role, but the absence of any evidence for lunar $\mathrm{H}_{2} \mathrm{O}$, the overall low $\mathrm{C}$ content of lunar rocks, and the $\mathrm{Pb}$ isotopic data argue for the former alternative.

Volatile release was not confined to the highlands or to the early stages of lunar crustal formation, as is shown by the vesicularity of many mare basalts. However, the clearest indications of volatile release accompanying volcanism in the maria are the large enrichments in $\mathrm{Zn}$, halogens, $\mathrm{Pb}$ [Tatsumoto et al., 1973; Silver, 1974], and other volatile elements in the Apollo 15 green glass (15426) and Apollo 17 orange glass (74220, Figure 8) samples. These are relatively homogeneous glasses, primarily in the form of $10-$ to $100-\mu \mathrm{m}$ spherical shapes and have moderately well defined ${ }^{40} \mathrm{Ar}$ ages [Huneke et al., 1973; Podosek and Huneke, 1973]. They are probably lunar volcanic glasses, and the associated volatile elements were incorporated at the time of eruption. There is evidence [Jovanovic and Reed, 1974; Tatsumoto et al., 1973; Silver, 1974; Grant et al., 1974] that the volatiles are on the surfaces of the spheres. However, the isotopic composition of the easily leached (Tatsumoto et al.) or volatilized (Silver) $\mathrm{Pb}$ in 74220 has a very high (nonradiogenic) ${ }^{204} \mathrm{~Pb}$ content. Thus the $\mathrm{Pb}$ 
must have originated at the time of the orange glass eruption in a source region that had a much lower $\mathrm{U} / \mathrm{Pb}$ ratio (i.e., a region much higher in volatile elements) than regions from which other lunar rocks were derived. Moreover, this source region must have remained isolated during the major period of crustal formation before $3.9 \times 10^{\circ} \mathrm{yr}$ ago in order to preserve this low $\mathrm{U} / \mathrm{Pb}$. This is strong evidence for significant chemical heterogeneities in the lunar crust and/or mantle. It is interesting that as is true with the volatile-rich highlands rocks, the $\mathrm{C}$ and $\mathrm{H}_{2} \mathrm{O}$ contents of the 74220 orange glass are extremely low [Epstein and Taylor, 1973]. This suggests that the moon formed from material with sufficient halogens, $\mathrm{Zn}, \mathrm{Tl}$, $\mathrm{Bi}$, etc., that after being outgassed during crustal formation these elements can attain concentrations approaching carbonaceous chondrite levels in some rocks. However, corresponding $\mathrm{C}$ and $\mathrm{H}_{2} \mathrm{O}$ enrichments are not observed, probably indicating that the initial lunar material was extremely depleted in $\mathrm{C}$ and $\mathrm{H}_{2} \mathrm{O}$.

Siderophile element abundance patterns. Lunar rocks are also depleted in siderophile elements, i.e., those elements that are known experimentally to concentrate in a metallic phase. Many of these elements (e.g., Ni and Ir) are highly nonvolatile; thus the overall depletion is undoubtedly related to their siderophile properties. Figure 9 summarizes the abundances of four key siderophile elements for which large bodies of data are available. Similar trends are present, as were noted for the volatile elements in the discussion of Figure 8. Although there is a wide spread in concentrations, the mare basalts show overall large depletions $\left(10^{-3}-10^{-4}\right.$ of $\mathrm{Cl}$ chondrites) despite the presence of small amounts $(\sim 0.1 \%)$ of native metal in the rocks. Although there is also a wide spread, many highlands rocks show concentrations of these elements which are 1-2 orders of magnitude larger than those of mare basalts. There appears to be little discussion in the lunar science literature of the possibility that the enhanced highlands rock abundances are more typical of the moon as a whole and that the low abundances of mare rocks represent differentiation of a metallic phase. Most lunar chemists prefer an alternative interpretation, following Anders and his co-workers, in which the indigenous levels of siderophile elements are regarded as being low, comparable to those of the mare basalts. The larger abundances in highlands rocks are interpreted as residual ancient meteoritic material from the period of intense highlands cratering and in particular, from large basin-forming impacts. [Morgan et al., 1974, 1975]. Siderophile elements are comparatively abundant in many meteorites; thus even if the incoming projectile is completely volatilized, the siderophile element content of the residual material will still show the meteoritic contribution. The arguments for this interpretation are as follows:

1. There are some highlands rocks that have a siderophile element content as low as that found in mare basalts but are similar in bulk and lithophile element chemistry to the siderophile-rich highlands rocks [Morgan et al., 1975]. Many of the latter rocks are breccias, whereas the former are "crystalline' (i.e., rocks showing an igneous texture, e.g., 76535) and pure anorthositic rocks, e.g., 15415. The siderophile-poor samples would represent uncontaminated highlands fragments that escaped brecciation during the period of intense bombardment. Crystalline rocks like 14310 or 68415 , which have high siderophile contents, are regarded as rocks crystallized from an impact melt. The siderophile elements reside in metallic grains [Wlotzka et al., 1972; Ganapathy et al., 1973], which are a discrete component in the breccias and in this sense can be

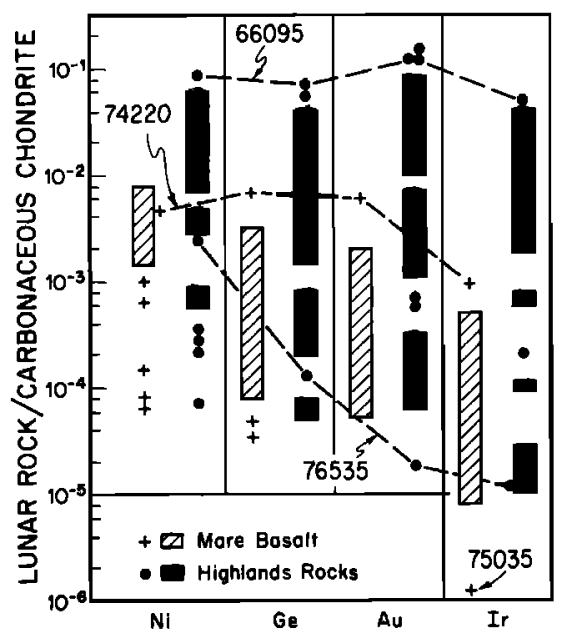

Fig. 9. Abundance patterns of four siderophile elements in lunar rocks relative to $\mathrm{Cl}$ carbonaceous chondrites. Analyses of soils and soil breccias have been excluded. Carbonaceous chondrite abundances have been taken from Ganapathy et al. [1970] for $\mathrm{Au}$ and Ir, Morgan et al. [1972] for Ge, and Baedecker et al. [1971] for $\mathrm{Ni}$. Individual analyses are plotted when it is possible. Bands indicate an essentially continuous distribution of data points. For samples of particular interest, analyses are connected by dotted lines. Rock 66095 is the volatile-rich 'rusty rock' (see Figure 7), 74220 is the Apollo 17 orange glass, and 76535 is a coarse-grained olivine-plagioclase rock believed to be of deep crustal origin. On this plot, rocks from the different missions do not separate well, although the Apollo 17 mare basalts tend to be concentrated at the bottom of the bands. In addition to 76535 the lowest concentrations in highlands rocks were found in some pure anorthosites, e.g., 15415 and 60025 ; however, other anorthositic rocks, such as 77017 and 78155 , have high concentrations. Data are from papers in the Lunar Science Conference proceedings papers of Anders and his coworkers, Wasson and his co-workers, and S. R. Taylor and his co-workers.

regarded as being extraneous to the silicate portions of the rock [Morgan et al., 1975].

2. Studies of radiation damage features indicate that a large number of highlands breccias, particularly those from Apollo 14, may contain small amounts of recognizable regolith materials, even though to a petrologist these may not be recognizable soil breccias [Hutcheon et al., 1972; MacDougall et al., 1973]. Meteoritic contributions of siderophile elements to mare soils are well documented (see section C [Morgan et al., 1975; Baedecker et al., 1974]). The thermal metamorphism accompanying the formation of a breccia would destroy most of the normal indications of regolith materials (impact glasses, particle tracks, solar wind rare gases) but would not affect the meteoritic siderophile element contribution. Thus even if only a residual trace of regolith material is present, it is quite plausible that large enrichments in siderophile elements will also be found. It should be emphasized that these breccias were formed $3.9 \times 10^{\circ} \mathrm{yr}$ ago; thus ancient regoliths are being discussed. A difficulty with the above argument is that a surprisingly large fraction of the highlands breccias would have to be composed of ancient regolith material. 
3. Given the impact origin of highlands breccias, it is probably unreasonable to believe that all of the material originally in the impacting objects would be lost to the moon. A few percent by mass of the breccias is required to be from the projectile; this requirement is reasonable. From this point of view, siderophile enrichments in highlands breccias were to be expected, and it would have been more surprising not to have found them.

Although the above arguments are plausible, I do not think that they are sufficient to rule out completely an indigenous origin for siderophile elements in highlands rocks. In particular, it is striking that the rusty rock 66095 and the orange soil 74220 , which are enriched in volatile elements (Figure 8) presumably of lunar origin, also have the high siderophile abundances (Figure 9), which are interpreted as being meteoritic. However, there are other rocks, e.g., 60025, that are rich in volatiles but very low in siderophile elements. Further, it is difficult to compile a list of arguments for an indigenous origin. In particular, it would be hard to understatld the variability in the relative abundances of the various siderophile elements [Morgan et al., 1974, 1975]. This may require a variety of chemically distinct metallic source regions in the lunar crust, somewhat reminiscent of the 'plum pudding' theory of the origin of iron meteorites. Even when one allows for the possiblilty of inhomogeneous accretion of materials to form the moon, it is not clear that in a well-differentiated lunar crust such metal pockets could remain chemically isolated.

Regardless of the origin of the siderophile elements in highlands rocks, two very interesting general observations can be made:

1. Lunar surface rocks are depleted in siderophile elements by at least a factor of 10-100 (Figure 9) in comparison with average solar system material.

2. The relative abundances of the siderophiles [Morgan et al., 1974, 1975] among themselves are highly variable and do not match abundance patterns for contemporary meteorites.

The first observation undoubtedly indicates that a metal phase has been separated sometime in the early history of lunar surface material. A major question that remains is, Exactly how did this happen, and where is the separated metal today? Perhaps siderophile elements are concentrated in a small lunar core (see the next section) or in widely disseminated pockets or plums in the deep lunar interior. However, given the limits on the mass of a metallic core set by the overall density and moment of inertia [Toksöz et al., 1974], unreasonable concentrations (percent levels) of siderophile elements in the core would be required for the moon as a whole to have average solar system abundances of these elements. It is more generally accepted that the separation occurred in the solar nebula [Anders et al., 1971] and that the residual metal is nowhere neat the orbit of the earth. It probably cannot be totally ruled out that the missing siderophiles reside today in the earth's core, although siderophile abundance patterns in terrestrial basalts appear to be distinct from those in lunar mare basalts [Anders et al., 1971].

Observation 2 above is of great importance because the relative abundances of the lithophile elements are qualitatively similar to those found in achondritic meteorites. However, the lunar siderophile abundance patterns suggest that there were early solar system materials that are chemically very different from those discovered through meteorite studies and that many fundamentally different materials remain to be discovered in the solar system.

Summary of lunar chemistry. In summary, because essen- tially total escape of volatile constituents from the moon during crustal formation appears to be less plausible, the underabundance of volatile elements compared with either lithophile refractory elements or carbonaceous chondrites is usually regarded as a property of the moon as a whole or at least the regions that were differentiated to form the lunar crust. Similarly, the low abundances of siderophile elements are best regarded as reflecting the separation of a metal phase from lunar material prior to the formation of the moon. This is undoubtedly a key factor in explaining the low density of the moon. The implied high-temperature history of lunar material can readily be reconciled with current ideas concerning chemical processes in the solar nebula, and several models have been discussed [Ganapathy and Anders, 1974; Anderson, 1973a; Wänke et al., 1974; Grossman et al., 1974; Taylor and Jakes, 1974].

\section{Density and Internal Structure of the Modin}

There are several excellent recent reviews of these subjects [Toksöz et al., 1974; Nakamura et al., 1974a; Lammlein et al., 1974]; they are also summarized here because of their importance. There are three physical properties of the moon that are known as a function of depth from direct measurement: the $P$ and $S$ wave seismic velocities [Toksöz et al., 1974; Nakamura et al., 1974a] and the electrical conductivity [Dyal et al., 1974]. The conductivity profile can be used to estimate the temperature profile for an assumed lunar interior composition. As for the earth, seismology provides the best look at the interior structure of the moon. Three types of seismic signals have been utilized: (1) man-made impacts of spacecraft [Toksöz et al., 1974], (2) meteorite impacts [Latham et al., 1973], and (3) lunar seismic events [Lammlein et al., 1974]. Most moonquakes are very weak by terrestrial standards (typically Richter magnitude 1) and are much less frequent (the seismic energy release of the moon is estimated to be $10^{-14}$ that of the earth). However, rare 'high-frequency teleseismic' events have reached magnitude 4 [Nakamura et al., 1974b].

The compressional wave seismic velocity profile in the upper $100 \mathrm{~km}$ of the moon (Figure 10), determined primarily from spacecraft impact data, shows two discontinuities, those at 20 and $55 \mathrm{~km}$. There is good evidence for both discontinuities, and the case for the $55-\mathrm{km}$ discontinuity is particularly strong [Toksöz et al., 1974]. Below $60 \mathrm{~km}$ it is not possible to fit all of the observed travel time data with a single velocity. Two choices are possible: 7.7 or $9.0 \mathrm{~km} / \mathrm{s}$. If the higher velocity is real, it either must be a regional layer or must be very thin $(\sim 40 \mathrm{~km})$ in order to match the velocity at deeper regions in the moon (see discussion below). The $55-\mathrm{km}$ discontinuity is taken to be the base of the lunar crust and is probably the lunar counterpart of the terrestrial Mohofovicič discontinuity. The particular profile shown in Figure 10 applies to the western mare regions and may not be typical of the whole moon. The $20-\mathrm{km}$ discontinuity can be interpreted as the depth of the mare basalts in this region. Laboratory $\boldsymbol{P}$ wave velocity measurements on lunar samples show no clear distinction between various lunar rock types (see compilation by Toksöz et al. [1974]); thus it is not possible to make firm compositional assignments to the observed crustal layers. However, the laboratory velocities are in approximate agreement with the measured crustal velocities, although the returned samples require higher pressures (equivalent to $\sim 50-\mathrm{km}$ depths) to reach the observed crustal velocity in the $20-$ to $50-\mathrm{km}$ depth range (see also the paper by Mizutani and Osako [1974]). This is probably because returned lunar samples are more highly frac- 


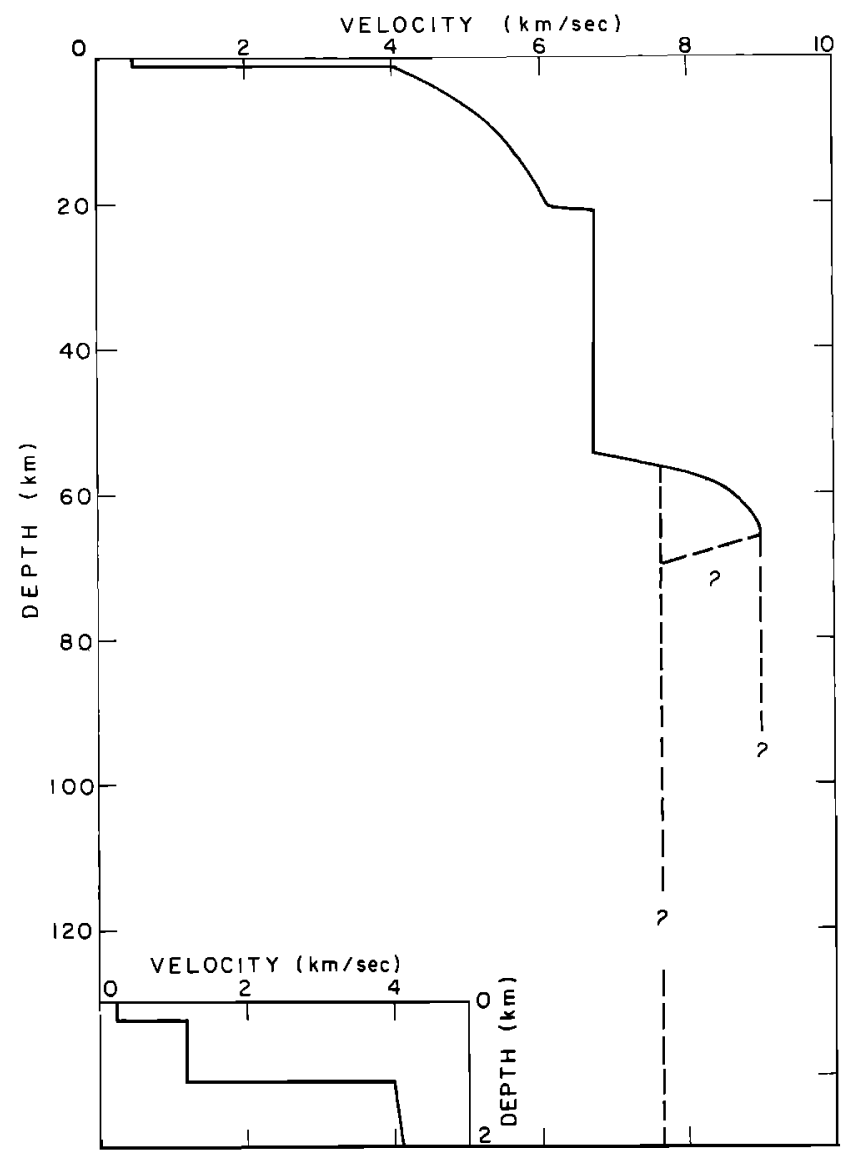

Fig. 10. Compressional wave velocity profile in the upper crust from Toksöz et al. [1974]. The velocities drop fairly rapidly above $20 \mathrm{~km}$ owing to increasing amounts of fracturing (impact?) of the crustal rocks. The discontinuity at $20 \mathrm{~km}$ marks the depth of the mare basalts, whereas the discontinuity at $55 \mathrm{~km}$ represents the base of the crust. There are two possible values for the velocity at the top of the mantle, as is indicated.

tured than the actual lunar crustal rocks, requiring higher pressure for pore closure.

However, the densities of lunar crustal rocks provide some constraints on the composition of the deep crust and on the nature of the $55-\mathrm{km}$ discontinuity. The densities of mare basalts are relatively high, $3.3-3.4 \mathrm{~g} / \mathrm{cm}^{3}$, reflecting the high $\mathrm{Fe}$ and $\mathrm{Ti}$ contents. Thus mare basalts are surprising materials to find on a planet with average density of $3.34 \mathrm{~g} / \mathrm{cm}^{3}$. However, the feldspar-rich highlands rocks will have densities of 2.8-3.1 $\mathrm{g} / \mathrm{cm}^{3}$ and are therefore much more plausible crustal materials. All crustal rocks are feldspar bearing and are thus unstable with respect to phase transitions at deep interior pressures [Ringwood and Essene, 1970; Anderson, 1973a, b]. However, prediction of the exact depths at which these transitions should occur is complicated by uncertainties in the temperature gradient and by the fact that there is a wide pressure range for the transition for feldspar-rich rocks [Anderson. $1973 a$ ]. Nevertheless, it is certain that mare basalts will undergo phase changes to rocks with densities of $3.5-3.7 \mathrm{~g} / \mathrm{cm}^{3}$ [Ringwood and Essene. 1970; Green et al., 1971], which are incompatible with the overall lunar density. Thus mare basalts cannot make up the deep interior regions of the moon. The situation for feldspar-rich highlands rocks is more complicated in that it may be possible for $\mathrm{Ca}$ - and Al-rich rocks of acceptable density to exist at depths of at least several hundred kilometers [Anderson, 1973a, b]. An interesting possibility is that the $9.0-\mathrm{km} / \mathrm{s}$ 'high-velocity zone' might represent a phase change from a feldspar-rich to a garnet-rich zone at $60 \mathrm{~km}$ but then revert back to a feldspar-bearing assemblage at a slightly greater depth because of the increase in temperature [Toksöz et al., 1974].

Figure 11 shows the seismic velocity structure of the deep interior of the moon, based on meteorite impacts and internal lunar seismic events. Velocity profiles calculated by Toksöz et al. [1974] and Nakamura et al. [1974a] are in overall good agreement, although the two groups differ in that Nakamura et al. report a discontinuity at $300 \mathrm{~km}$ that they propose as the base of the zone from which the crust has been differentiated. Magnesium-rich olivine and orthopyroxene mixtures provide a good match for the average seismic velocity and the density of the mantle above $\sim 700 \mathrm{~km}$ from the center. Pure olivine compositions are possible but not pure orthopyroxene. The $\sim 8-\mathrm{km} / \mathrm{s}$ average mantle $P$ velocity is somewhat low in comparison with estimates for $\mathrm{Ca}$ - and Al-rich rocks [Anderson and Kovach, 1972] unless temperatures higher than those estimated by Toksöz et al. [1974] are adopted.

For seismic ray paths that pass within about $700 \mathrm{~km}$ of the center, shear waves are highly attenuated (Figure 11). The effect on the $P$ wave velocity is much less. This behavior is similar to that of the asthenosphere (low-velocity zone) of the earth and may also represent a partially molten zone in the lunar interior. Alternatively, it could represent a volatile-rich, undifferentiated lunar 'core.' This latter alternative, if it were true, would require a spectacular chemical contrast between the inner and the outer portions of the moon and would probably indicate some kind of inhomogeneous accretion for the moon. On the other hand, a partially molten lunar interior

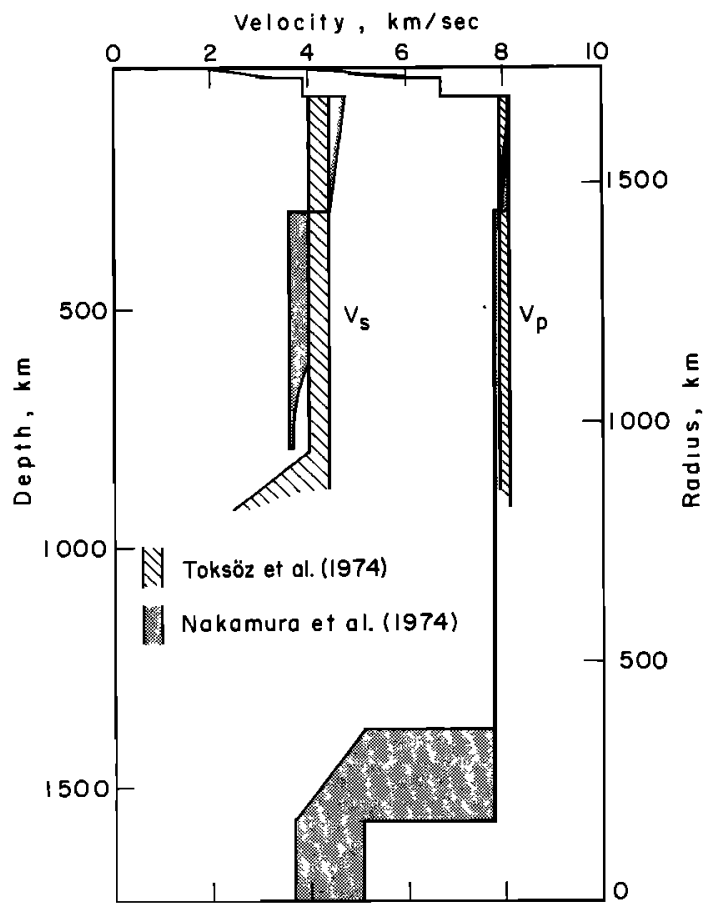

Fig. 11. Velocity profiles in the deep lunar interior as determined by natural seismic events. Profiles as calculated by Toksöz et al. and by Nakamura et al. are in reasonable agreement. The strong attenuation of $S$ waves at $7-$ to $800-\mathrm{km}$ radius is interpreted as the onset of partial melting. The dip in $P$ velocity at $2-$ to $300-\mathrm{km}$ radius may indicate a small molten core. Figure is from Toksöz et al. [1974]. 
does not appear to violate any geophysical or geochemical constant and can quite easily be reconciled with thermal history calculations [Toksöz et al., 1974]. This is the more plausible and more widely accepted alternative at present.

A single meteorite impact event on the extreme back side of the moon has shown a decrease in $\boldsymbol{P}$ wave velocities for rays traveling through the innermost $20 \%$ of the moon (Figure 11) [Nakamura et al., 1974a]. No $S$ waves were detected. If additional events confirm the drop in $P$ wave velocity, it will indicate that the moon does have a small liquid core. A molten iron core of up to $30 \%$ of the lunar radius ( $5 \%$ by mass) is compatible with the lunar density and moment of inertia. Similarly, an FeS core of $40 \%$ in radius and $8 \%$ by mass would be possible [Toksöz et al., 1974]. Thus the core indicated by the Nakamura et al. data could be either metal or sulfide [Brett, 1973]. Conceivably, this is the home of some of the siderophile and/or chalcophile elements that are highly depleted in lunar surface rocks.

The longevity of the lunar seismic network has paid off handsomely.

\section{Evolution of the Moon}

Figure 7 displays the age distribution of lunar rocks as obtained from ${ }^{87} \mathrm{Rb}-{ }^{87} \mathrm{Sr}$ internal isochrons [Tera et al., 1974a]. This remarkable age pattern was totally unexpected and warrants detailed discussion. (All ages in the following discussion will be given in units of $10^{\circ} \mathrm{yr}$.)

At least one lunar rock (72417) has survived the initial crustal formation. This is a dunite (95\% olivine) that was sampled as a fragment from a breccia boulder at the base of the highlands massifs during Apollo 17. It has an Rb-Sr isochron age of $4.6 \times 10^{9} \mathrm{yr}$, although it is shocked [Albee et al., 1974]. Petrologically, it appears to be a cumulate rock that formed in at least the deeper parts of the crust. The more recent violent history of the region in which this rock formed failed to disturb completely the initial Rb-Sr systematics. This rock in itself demonstrates very early igneous activity on the moon, probably marking the initial differentiation of the lunar crust in the period 4.4-4.6. Other rocks, e.g., 12013 [Lunatic Asylum, 1970], 65015 [Papanastassiou and Wasserburg, 1972b], and 76055 [Tera et al., 1974b], can be interpreted as rocks originally formed at 4.4-4.6 but extensively reheated at about 3.9. Only a few rocks have ages in the time span between 4.0 and 4.6 [Bogard et al., 1974; Husain and Schaeffer, 1975]. The record of this period of lunar history appears for the most part to have been totally obliterated. The intense activity terminated in the period $3.85-4.0$ on the basis of ages of highlands rocks from Apollo 14, 15, 16, and 17 and Luna 20, and it appears that most highlands rocks have ages of 3.85-4.0, although more samples are required to verify this, particularly from the lunar far side.

Fra Mauro (Apollo 14) rocks are samples of a region interpreted as a ridge of ejecta produced by the impact event that formed the Imbrium basin (Figure 1). This interpretation is vital to our present understanding of the moon and should be subjected to further photogeologic study. As judged from the 3.2 ages (Figure 7) for Apollo 15 mare basalts, the lava flows that filled the basin to produce Mare Imbrium occurred long after the formation of the Fra Mauro rocks. Strictly speaking, the age of the Imbrium impact is bracketed between 3.2 and 3.85 , but 3.85 is usually adopted as the time of the Imbrium impact because (1) an impact large enough to produce a 500 $\mathrm{km}$-diameter crater should produce strong heating and some melting of the ejecta, (2) most of the Apollo 14 rocks are im- pact breccias, and (3) K-Ar ages, which are sensitive to reheating, are also in the range 3.85-3.95 [Turner et al., 1971]. Mare Imbrium is the second youngest (after Mare Orientale) of approximately 40 major lunar impact basins [Howard et al., 1974]. The intense bombardment of the moon by these and innumerable smaller impacts sculptured the lunar surface in the period between 4.6 and 3.9, producing the rugged highlands topography and obliterating most of the record of lunar igneous activity in that period. The ages of mare basalts are only slightly younger than those of highlands rocks; this finding is very surprising in view of the very large difference in crater densities. Quantitative comparison of the ages (Figure 7) for the various landing sites and the corresponding density of large impact craters in the same regions [Boyce et al., 1974] shows that there is a large increase in crater density for times older than 3.5. It had long been acknowledged that impact rates might be higher earlier in the history of the solar system, but such a dramatic increase was totally unexpected. Further, because the collisional lifetimes of objects in earth-crossing orbits are estimated to be $10^{6}-10^{7}$ yr at most [Wetherill, 1974], it was also a major surprise to learn that the intense early bombardment of the moon (and the earth), as recorded in the lunar highlands crater density, had extended to times up to $0.7 \times 10^{9}$ $\mathrm{yr}$ after the formation of the solar system. It may be that the moon was subjected to an intense pulse of bombardment at $\sim 4$ $\times 10^{9} \mathrm{yr}$ ('terminal cataclysm' [Tera ét al., 1974b; G. W. Wetherill, unpublished manuscript, 1974]).

Basalt samples from five of the major maria (Figure 7) show a relatively small range in age from 3.3 (Apollo 12 and 15) to $3.9 \times 10^{\circ} \mathrm{yr}$ (Apollo 11 low K rocks [Tumer, 1970; Eberhardt et al., 1974]). The major point is that there appears to be a cessation of igneous activity as $~ 3.2$ [Papanastassiou and Wasserburg, 1971]. Comparison of relative crater densities for the youngest regions on the moon with those of the mare landing sites, when one allows for a time-dependent bombarding flux, indicate that the youngest mare flows would be $\sim 2 \times 10^{\circ} \mathrm{yr}$ [Boyce et al., 1974].

A unique, unanticipated thermal history for the moon is indicated. Independent of specific models, the differentiation accompanying crustal formation must have begun no later than $\sim 4.4$. Whether crustal formation occurred suddenly at 4.4-4.5 or continuously down to 4.0 is not clear at present. There are some rocks intermediate in age, particularly the troctolite 76535 , which appears to be a deep crustal cumulate rock that formed at about 4.3 [Bogard et al., 1974; Husain and Schaeffer, 1975], but it is not clear whether or not these are rare interlopers.

There is no evidence for highlands magmas of either internal or impact origin at times later than 3.85 (determined by 68415 [Papanastassiou and Wasserburg, 1972b]). The time of initial lava flows in the mare basins is unknown, but the oldest sampled surface flows are $~ 3.9$. Basin filling appears to have terminated at about 2-3. And then nothing? Today the moon is extremely quiet. It is solid down to depths of $1000 \mathrm{~km}$ with seismic activity $10^{-14}$ that of the earth (see the previous section). Why should (and how can) a planetary-sized body go through $1.5 \times 10^{\circ} \mathrm{yr}$ of intensive igeneous activity and then stop? The earth has been thermally violent throughout its history and continues active until the present day. The parent bodies of most meteorites formed very rapidly $4.6 \times 10^{9} \mathrm{yr}$ ago and showed no further activity. A specific lunar thermal history that çan reproduce these general requirements is a matter of theoretical calculation, and many papers on this subject have been written [e.g., Toksöz and Solomon, 1973], but there 
is a general consensus among the various calculations that the initial temperature gradient in the moon was peaked toward the surface, permitting early igneous activity, but that the inside was relatively cool, permitting the deeper regions to cool fairly rapidly and igneous activity to cease.

\section{Summary and Epilog}

The preceding discussion attempted to outline what progress has been madê in answering the list of 'fundamental problems' given in the introduction. In addition to summarizing this discussion it is also important to consider what remains to be done.

We now have a good basic characterization of the nature of highlands and mare materials. Thus it is not premature to regard these as the data that must be described by petrogenetic models, and inspection of the Proceedings of the Fifth Lunar Science Conference reveals that much work has already been initiated. Key problems are (1) the nature of the source regions of the mare basalts and the role of near-surface differentiation [Hays and Walker, 1975], (2) the possible association of the highlands rocks with major impact basins, and (3) the origin of the highlands crystalline rocks, allowing for the possibility of impact melting. However, because of the pace of the lunar missions it was not possible to distribute all lunar samples for study; thus it is an equally important post-Apollo task to insure that fundamentally different types of lunar materials have not been overlooked and that the remaining samples are in accord with the patterns established to date.

The evidence is very strong that the moon is a differentiated planet, as is the earth. The moon has a crust enriched in lithophile elements that was derived from a source region depleted in volatile substances, including the alkali elements. Key element ratios, e.g., $\mathrm{K} / \mathrm{U}$, appear to be approximately preserved in planetary differentiation processes and thus can be used as 'planetary constants.' Interestingly, some of these ratios, e.g., $\mathrm{K} / \mathrm{U}$ and $\mathrm{Pb} / \mathrm{U}$, are different for the moon and the earth; this puts a serious constraint on the relative origins of the two planets. The experiments of Metzger et al. [1974] have demonstrated that by using the gamma rays from their radioactive decay, $K, U$, and $T h$ can be determined from an orbiting spacecraft, documenting an important chemical probe for planets in general. In the western mare regions the lunar crust extends to a depth of $\sim 60 \mathrm{~km}$, underlying $20 \mathrm{~km}$ of mare basalt [Toksöz et al., 1974]. The lunar crust is much thicker than that of the earth and is probably compsed primarily of feldspar-rich rocks. The composition of the lunar interior cannot be uniquely determined but is strongly constrained by the seismic velocity and density. For example, mixtures of $\mathrm{Mg}$-rich olivine and pyroxene match the properties of the lunar interior well, but a fairly narrow range of composition is required. The amount of the lunar interior that must be differentiated to produce the crust is model dependent. In general, estimates could range from zero (for an extreme inhomogeneous accretion model defended by no one at present) to the whole moon [Wood, 1975 (this is compatible with thermal models); Toksöz and Solomon, 1973]. More typical estimates tend to be in the range of hundreds of kilometers, e.g., $400 \mathrm{~km}$ [Ringwood and Green. 1974]. A seismic velocity discontinuity has been proposed at 300-km depth by Nakamura et al. [1974a], which might mark the depth of the zone from which the crust was differentiated.

The strong attenuation of $S$ waves beneath $1000-\mathrm{km}$ depth might indicate a fundamentally different, possibly volatile-rich interior; however, a partially molten zone, analogous to the earth's asthenosphere, is the more popular interpretation. Some evidence exists [Nakamura et al., 1974a] for a small molten core that could be either Fe or FeS [Toksöz et al., 1974]. The presence of a lunar core may account for some of the depletions of siderophile and/or chalcophile elements in lunar surface rocks.

The prime future task is to convert the qualitative observations cited here into a quantitative chemical history for the moon. Many ideas on this subject have already been proposed (see, for example, volume 2 of the Proceedings of the Fifth Lunar Science Conference). Refined seismic data on the nature of the lunar interior are required, and the permanent existence of a seismic network is crucial.

The evolutionary history of the moon was characterized by a period of relatively intense igneous activity that terminated $2-3 \times 10^{\circ}$ yr ago. Intense meteoritic bombardment of the lunar surface has obscured the igneous record for times older than about $4 \times 10^{\circ} \mathrm{yr}$. Most thermal history calculations for the moon [Toksöz and Solomon, 1973] seem to require an initial temperature gradient peaked toward the surface. It is very important to see whether this type of temperature gradient is inescapable in order to account for the present structure, composition, and evolution of the moon. Two methods have been proposed to account for such a gradient: (1) rapid accretion of small, cold grains in which the rate of gravitational energy release in the terminal stages of growth is too rapid for efficient radiative cooling [Hanks and Anderson, 1968] or (2) inductive heating of an initially cold moon in an intense early solar wind [Sonett et al., 1969]. Both of these mechanisms have the common property that the moon formed basically cold and was heated only in the final stages of growth (rapid accretion) or after formation (inductive heating). Contemporary planetary scientists have generally agreed that some type of cold accretion is the most plausible way for planets to form, but if it can be shown that this must be true for the moon, this will constitute a major advance.

\section{Unanticipated Results from Apollo}

The results to be presented in this section are equally as important as the topics discussed in section B. From the list given in the introduction, items 1 and 2 have already been discussed in sections B4 and B1, respectively. The remaining items will be discussed below in their order in the original list.

\section{Ancient Paleomagnetic Field}

Lunar magnetism is covered in recent detailed reviews by Fuller [1974] and Dyal et al. [1974a]. Based on measurements from the orbiting subsatellite launched by Apollo 15, the present-day global dipole field of the moon is less than $10^{-6}$ of that of the earth [Russell et al., 1974]. However, local surface fields approximately $1 \%$ of those of the earth were found during Apollo 16 [Dyal et al., 1973], and regions of high magnetic fields have been observed from orbit, particularly near the crater Van de Graaff on the lunar far side [Sharp et al., 1973]. These high local fields are a reflection of a high degree of natural remanent magnetism observed in many lunar samples. The remanent magnetism is usually interpreted as being thermal in origin, thus indicating the presence of an ambient magnetic field at the time that the lunar samples cooled below the Curie point $\left(750^{\circ}-800^{\circ} \mathrm{C}\right)$. Paleointensity estimates of the required fields give values of 0.05 to several times the terrestrial field [Gose et al., 1973; Stephenson et al., 1974]. Some of the measurements are on breccias (e.g., 15498) whose most recent time of heating is not clear and could be quite recent. 
Other measurements are on Apollo 16 crystalline rocks and mare basalt samples [Stephenson et al., 1974] for which it is quite likely that the time of final cooling is given by the crystallization age. Taken at face value, these data qualitiatively indicate that sizable magnetic fields existed at the lunar surface $3-4 \times 10^{\circ}$ yr ago, which are totally absent today. However, quantitative estimates of paleofields are complicated by the effects of the detailed thermal history of a given rock, in particular, shock [Fuller, 1974; Cisowski et al., 1974; Brecher et al., 1974]. For example, Apollo 17 mare basalts of the same age show an order of magnitude variation in the derived paleomagnetic intensities even from the same laboratory [Stephenson et al., 1974; Brecher et al., 1974].

Depending on how it is assumed to originate, an ancient lunar magnetic field can lead to very different views of the early thermal history of the moon. If the field were due to a molten metal core [Pearce et al., 1972], then the interior of the moon would initially have been hot $\left(1600^{\circ}-1700^{\circ} \mathrm{C}\right)$, and it is not clear whether the outer portions would cool rapidly enough to cause igneous activity to cease at $\sim 3 \times 10^{\circ} \mathrm{yr}$ ago and to support the gravitational anomalies represented by the mascons [Toksöz and Solomon, 1973; Toksöz and Johnston, 1975]. Alternatively, it has been postulated that the moon was initially below the Curie point at all portions of the interior and was magnetized by a transient early solar system magnetic field [Strangway and Sharp, 1974]. The moon was presumably still magnetized in the interior throughout the duration of mare filling, but as the interior temperature rose through the Curie point, the magnetic field vanished. Resolution of these alternatives appears to require reliable quantitative paleofield determinations in order to determine the time dependence of the paleofield.

If there is a small molten core in the inner $100-200 \mathrm{~km}$ of the moon today (section B3), it does not appear to generate an appreciable magnetic field. According to Brett [1973] an Fe-FeS eutectic mixture has sufficient conductivity and magnetic permeability to produce a magnetic field for the present rotation rate of the moon. A much larger rotation rate would be required for a pure FeS core. If the ancient lunar magnetic field were due to a molten core and if the core still exists, the moon is required to have had a much more rapid rate of rotation in the past. The decay of the ancient field might reflect a decrease in the rotation rate.

\section{Exotic Components in the Regolith}

With the possible exception of a few Apollo 15 rocks from the edge of Hadley Rille, which may be bedrock samples, all returned lunar samples were impact-derived fragments sampled from the debris layer (regolith) that makes up the outer $\sim 10 \mathrm{~m}$ of the lunar surface. Except for impact-produced glasses the finer-sized ( $\leq 1 \mathrm{~mm}$ ) particles (soils) might be expected to be no more than comminuted material from the larger rock fragments. To a first approximation this is true; however, the fascinating area of 'regolith studies' derives much of its energy from the fact that a lunar soil contains much more than broken rock fragments. Only a few examples of research from this area are discussed.

Kreep. The first lunar soil from Apollo 11, 10084, had Rb and $\mathrm{Sr}$ contents and a $\mathrm{Sr}$ isotopic composition that could not be explained by mixtures of the local rocks [Papanastassiou et al., 1970]. An 'exotic component' that was comparatively rich in $R b$ was required. Relatively small, but definite enrichments in $\mathrm{K}, \mathrm{Cs}$, and $\mathrm{Ba}$ were also required [Tera et al., 1970]. Studies of millimeter-sized fragments revealed rare alkali feld- spar-glass-low Ca pyroxene fragments [Albee and Chodos, 1970], which could account for the chemical and isotopic properties in the soil. These fragments were the first evidence for highly differentiated, graniticlike materials in the lunar crust. Similar studies of Apollo 11 coarse fines led to the discovery of anorthositic fragments, which are probably ejecta from highlands areas into the maria [Wood et al., 1970]. A pollo 12 returned soils for which the presence of an exotic component was no longer subtle. The $K$ contents of Apollo 12 soils are 3-5 times higher than those of the local mare basalts owing to the presence of light-colored glassy particles named Kreep, because they were rich in many lithophile elements, including $\mathrm{K}$, rare earths, and phosphorous [Meyer et al., 1971]. A single large rock, 12013, which is the closest lunar analog to a terrestrial granite, was also returned [Lunatic Asylum. 1970; Drake et al., 1970]. The Apollo 12 site was located on a light-colored ray from the large crater Copernicus, $370 \mathrm{~km}$ distant, and this is a plausible source for these materials. These studies emphasize the importance of lateral transport by impact for the moon and presumably for other atmosphereless planets. Because of lateral transport, a sample from any one spot gives information about materials from a much wider region.

Missions subsequent to Apollo 12 returned many $\mathrm{K}$-rich rocks that have been called Kreep, although it is not clear that they represent a single rock type. In missions where there were local sources of K-rich rocks (Apollo 14, 16, and 17), it has been possible to account for the lithophile element chemistry of the soils in terms of mixtures of local rocks [Warner et al., 1974; Rhodes et al., 1974]. For the mare soils from Apollo 15 an external component is again required. Orbital gamma ray data show that the extremely K-, U-, and Th-rich areas tend to be concentrated in the near side regions around Mare Imbrium [Metzger et al., 1974].

Implanted solar ions and regolith mixing. Highly volatile elements, such as rare gases, are essentially absent from lunar rocks but are relatively abundant constituents in the solar wind. In the absence of an atmosphere or a significant global magnetic field the solar wind impinges directly on the lunar surface. Given their low energy ( $\sim 1 \mathrm{keV} /$ nucleon), the solar wind ions will penetrate only a few hundred angstroms and thus will not be present in interior rock samples. However, because of mixing of the regolith by small impacts, many of the grains of a soil sample will have been exposed directly to the solar wind. Consequently, the concentrations of rare gases in soil samples are many orders of magnitude higher than those in rocks [Eberhardt et al., 1972]. Moreover, the isotopic compositions of the rare gases from interior rock samples show that they are formed primarily from galactic cosmic ray nuclear reactions, and these isotopic compositions are very distinct from those found in soils. Thus the solar wind rare gases are qualitative tracers for exposure of material to the outermost layers of the lunar surface. The efficiency of the impact mixing process is shown by the fact that roughly uniform solar wind gas contents are found at depths down to $3 \mathrm{~m}$ in the deep core samples, indicating that regardless of present depth, most of the material at one time resided on the lunar surface [Bogard et al., 1973; Eberhardt et al., 1974]. Similar conclusions are reached from measurements of tracks produced by solar flare heavy ions (10- to $100-\mathrm{MeV} /$ nucleon Fe nuclei) that penetrate only $\sim 100 \mu \mathrm{m}$, except that evidence of discrete depositional events is found in some cases [Arrhenius et al., 1971; Fleischer et al., 1971; Crozaz et al., 1974]. The best information on the depositional history of the core samples is 
provided by studies of neutron capture products because neutron capture occurs primarily at meter depths rather than at the surface [Russ et al., 1972; Russ, 1973; Curtis and Wasserburg, 1975] and because neutron capture rates are well known [Woolum et al., 1975].

The relative abundances of the rare gases show considerable variation among lunar soils and also for mineral separates of a given soil [Hintenberger et al., 1974]. Moreover, the lighter rare gases appear to be depleted in comparison with either estimated solar system abundances or the relative $\mathrm{He} / \mathrm{Ne} / \mathrm{Ar}$ abundances measured directly in the solar wind foil experiments during Apollo 11-16 [Geiss, 1973]. This shows that at least the lighter rare gases are not quantitatively retained. The order of magnitude of the solar wind Xe concentrations is consistent with no loss of solar wind $X e$ from the moon over $\sim 4 X$ $10^{\circ} \mathrm{yr}$, if the $\mathrm{Xe}$ is assumed to be distributed through a typical regolith depth of $\sim 4 \mathrm{~m}$ [Burnett et al., 1971a; Geiss, 1973]; however, by noting that the amounts of solar wind Xe are high in relation to the amounts of Xe produced by cosmic ray nuclear reactions, Geiss [1973] has proposed an increase in the solar wind flux in the past. Other authors have emphasized that the concentrations of cosmic ray reaction products, particularly those due to neutron capture, are low in comparison with what would be predicted from simple ideas of regolith mixing [Eugster et al., 1970; Burnett and Woolum, 1974; Curtis and Wasserburg, 1975]. This may or may not invalidate the conclusion of Geiss depending on the origin of the low concentrations of cosmic ray reaction products. More sophisticated estimates of regolith vertical mixing rates [Gault et al., 1974] appear too slow to explain the observed cosmic ray product data, and this is an area of intensive research at present.

Large concentrations of $\mathrm{H}$ (approaching $1 \mathrm{~cm}^{3} \mathrm{H}_{2} / \mathrm{g}$ ) are found in lunar soils, undoubtedly of solar wind origin [Epstein and Taylor, 1973]. Most interestingly, the hydrogen appears to be $\mathrm{D}$ free (less than 0.1 of the terrestrial $\mathrm{D} / \mathrm{H}$ ratio), confirming theoretical astrophysical predictions that $D$ would be destroyed by thermonuclear reactions in the early stages of solar evolution. Since the solar $D$ is converted to ${ }^{3} \mathrm{He}$, the solar wind ${ }^{3} \mathrm{He} /{ }^{4} \mathrm{He}$ ratio (as measured in the solar wind foils), combined with an estimate of the solar ${ }^{4} \mathrm{He} / \mathrm{H}$ ratio, gives an upper limit for the $\mathrm{D} / \mathrm{H}$ ratio of $3 \times 10^{-5}$, which is 5 times less than the terrestrial ratio, showing that the formation of the earth resulted in extensive isotopic fractionation of $\mathrm{H}$ [Geiss, 1973].

Both the absolute and the relative $\mathrm{C}$ and $\mathrm{N}$ concentrations in lunar soils are consistent with the bulk of these elements also being of wind origin [Kothari and Goel, 1973]. This is actually somewhat surprising, and the lack of a clear lunar component indicates, as was discussed in section B2, that lunar crustal enrichment in other volatile elements, such as $\mathrm{Zn}$ and $\mathrm{Tl}$, was not accompanied by $\mathrm{N}, \mathrm{C}$, and $\mathrm{H}_{2} \mathrm{O}$ enrichment, showing that the moon as a whole is very depleted in these. Also, the lack of a clear meteoritic contribution is important, as is discussed in the following section.

The chemistry of $\mathrm{C}$ in a lunar soil sample is complicated but fascinating. Most of the carbon released in a pyrolysis experiment is emitted as $\mathrm{CO}$, but this may be formed during the heating [DesMarais et al., 1973]. Some $\mathrm{CH}_{4}$ is present, because this gas is released when lunar soils are attacked with deuterated acids that contain no hydrogen [Cadogan et al., 1972]. The presence of 'carbide'-like material is inferred because $\mathrm{CD}_{4}$ is also released in these experiments. The actual nature of the $\mathrm{C}$ compounds formed by solar wind implantation may be clarified by simulation experiments now underway in many laboratories.

Meteoritic material. For all the mare sites it has been found that the concentrations of volatile and siderophile elements in soils are much higher, by factors of 10-100, than those found in the mare basalts [Morgan et al.. 1975; Baedecker et al., 1974]. Because of high concentrations of many of these elements in highlands rocks it is more difficult to establish corresponding enrichments in Apollo 14 and 16 soils. Solar wind contributions should be negligible; thus there are three plausible sources for the excesses: (1) lateral transport from highlands regions where rocks rich in these elements are found, (2) local volcanic activity, and (3) residual meteoritic material. All three of these sources are viable mechanisms for the volatile elements and may contribute to some degree. For siderophile elements there is no evidence that under lunar conditions they would be concentrated in volcanic vapors or pyroclastic eruptions, and so alternative 2 looks less probable. Similarly, the mare soil concentrations are comparable $\left(\sim 10^{-2}\right.$ carbonaceous chondrite levels) to the volatile-rich highlands rocks. Unless much of the mare soil is really of highlands origin, lateral transport cannot explain the siderophile element concentrations. This same agrument may not hold for volatile elements, because it is conceivable that these can be 'distilled' from the highlands rocks during impact, and once they are in the lunar atmosphere, they may be deposited and 'released' from surfaces several times before becoming chemically 'fixed.' This would cause volatile elements to be dispersed more widely following impact volatilization than less volatile constituents. Thus for siderophile elements most lunar scientists accept a meteorite origin, at least for mare soils. This is further supported by the relative abundances of the siderophile elements, which as is shown in Figure 12, correspond to those found in $\mathrm{Cl}$ carbonaceous chondrites and are distinct from those found in highlands rock samples. Approximately $1 \%$ of meteoritic material in a mare soil is indicated. Many volatile elements, e.g., Sb, Se, Ag, Te, and Bi, despite the possibility of alternative sources, show abundances of $\sim 10^{-2} \mathrm{Cl}$ levels, also compatible with being primarily of meteoritic origin [Morgan et al., 1975]. There is a general scatter of about a factor of 2 in the Cl-normalized abundances, with no consistent indication of systematic variations of siderophile relative to volatile elements. If $1 \%$ of $\mathrm{Cl}$ meteoritic material were added to mare soils, the resulting $\mathrm{C}$ and $\mathrm{N}$ concentrations should be 300 and $20 \mathrm{ppm}$, respectively. This presents no problem for $\mathrm{N}$, but typical mare soil carbon contents are 50-200 ppm [Moore et al., 1974]; moreover, the carbon abundances can be explained by solar wind contributions. It appears that either (1) the added meteoritic material is not predominantly $\mathrm{Cl}$ carbonaceous chondrites but another type of meteorite with less $C$ but with similar relative abundances of siderophile elements [Morgan et al., 1975], (2) C is selectively lost from the moon during impact, in comparison with other volatile elements, (3) $\mathrm{C}$ is preferentially lost from the regolith after deposition by diffusion or solar wind sputtering, or (4) we are being fooled by the consistency in relative abundances (Figure 12), and all of the siderophile and volatile elements in the soils are lunar in origin from an as yet unforeseen source. The consensus among workers in this area is that explanation 2 is correct, but all of these alternatives and the general question of the sources and chemical distribution of $\mathrm{C}$ and $\mathrm{N}$ in lunar soils have important implications and deserve further study. Item 4 is perhaps the most exotic because it would imply that there is essentially no 

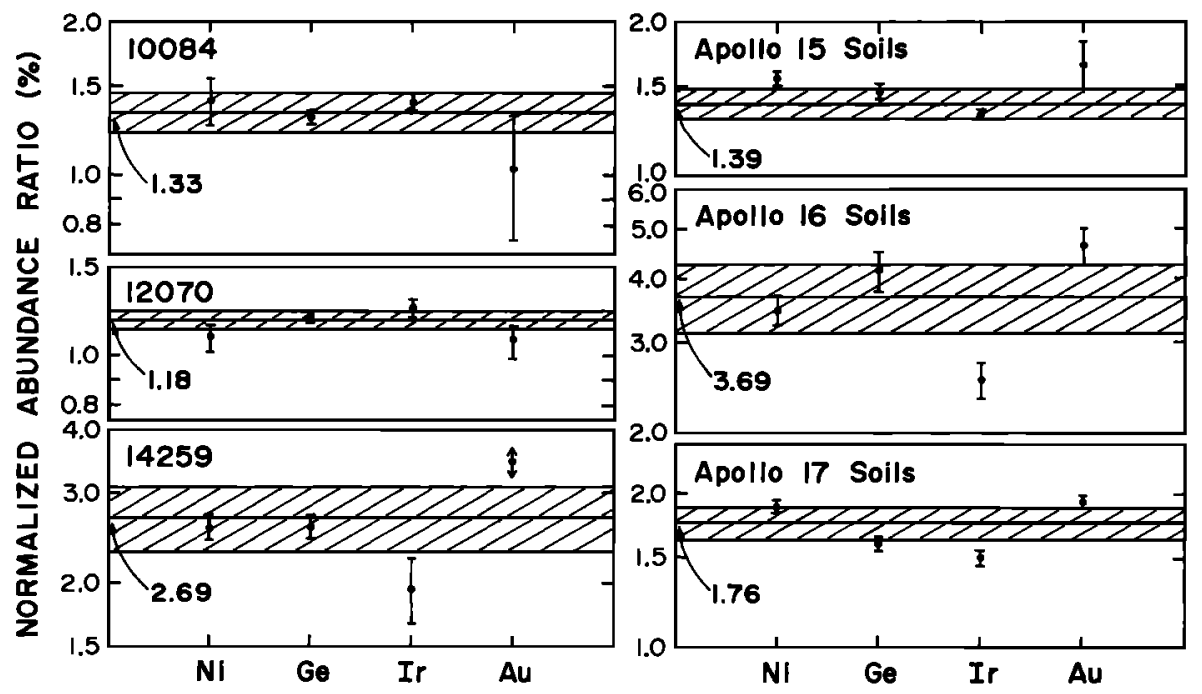

Fig. 12. Relative abundances of four siderophile elements in Apollo soils (10084, Apollo 11; 12070, Apollo 12; and 14259, Apollo 14), expressed as percent of $\mathrm{Cl}$ carbonaceous chondrite abundances. Figure is from Baedecker et al. [1974]. Corrections have been made for contributions from local rocks. Except for Apollo 14 and 16 these corrections are small and unambiguous. The roughly flat pattern is interpreted as showing that a few percent of these soils could be residual meteoritic material.

record whatsoever left on the moon of all the meteorites that produced the intensely cratered terrain.

\section{Fundamentally Different Material on Lunar Surface Layers-Properties of the Outer Micron}

The preceding section indicates that many of the interesting properties of lunar soils are related to the possibility of deposits on the surfaces of grains; thus the present topic really cannot cleanly be separated from the general area of regolith studies. I have arbitrarily singled out the physical and chemical properties of the first micron of the lunar surface as viewed from space for special discussion, because I feel that it is a very interesting area for further research.

The outer micron of the lunar surface is subjected to a bewildering variety of processes: (1) solar wind implantation, (2) deposition of atoms from a transient lunar atmosphere produced by impact volatilization or outgassing events, (3) 'reimplantation' of ions produced by ionization of atmospheric constituents, (4) thermal diffusion of the emplaced species (probably radiation damage controlled), (5) chemical changes (reduction) during or subsequent to emplacement, (6) deposition of submicron, molten 'accretionary' particles, (7) erosion of the surfaces by solar wind sputtering, and (8) destruction of the surface layers by impact melting with redistribution of surface constituents throughout the volume of the particles (glasses and agglutinates) formed.

Surfaces exposed to the solar wind are expected to become saturated $\left(10^{16}-10^{17}\right.$ ions $\left./ \mathrm{cm}^{2}\right)$ with implanted $\mathrm{H}$ and $\mathrm{He}$ in times of 10-1000 yr [Bibring et al., 1974; Maurette and Price, 1975]. Thus the chemistry of the outer micron should be heavily influenced by implanted solar wind. Further, as first documented by the studies of Borg et al. [1971], the implantation process systematically destroys crystal lattices, producing an amorphous coating with thickness comparable to the solar wind implantation depths, 200-500 $\dot{\mathrm{A}}$. These authors showed that a surprisingly large number of $\sim 1-\mu \mathrm{m}$ soil grains had amorphous coatings when they were viewed under a highvoltage transmission electron microscope. The amorphous layers and the constituents that they contain have a finite lifetime of $\sim 10^{\mathrm{s}} \mathrm{yr}$ (while directly exposed on the surface) because the production of the amorphous layer by implantation and destruction by sputtering are in equilibrium. Once it is buried, even a few microns, the lifetime of the layer itself is determined by its recrystallization rate. The concentrations and distribution of the constituents are determined by diffusion and chemical reaction rates. Little is known about any of these rates. Preferential loss, presumably by diffusion, of light constituents is shown by the low measured $\mathrm{H} / \mathrm{He}$ and $\mathrm{He} / \mathrm{Xe}$ ratios, which are about $1 \%$ of those estimated from solar abundances [Geiss, 1973]. As far back as Apollo 11, evidence for postimplantation redistribution of solar wind rare gases was shown by etching experiments [Eberhardt et al., 1970] and by mass spectrometric measurement of rare gases released during electron beam volatilization of individual soil grains [Kirsten et al., 1970]. Both experiments showed that appreciable concentrations of rare gases existed at depths up to $1 \mu \mathrm{m}$, or roughly 100 times the solar wind penetration depth. Figure 13 shows a quantitative profile of redistributed solar wind $\mathrm{H}$, as measured using a nuclear resonant reaction technique for a surface sample of lunar rock [Leich et al., 1974]. Relatively large H concentrations are observed to depths as great as $0.4 \mu \mathrm{m}$, or over 10 times the range of solar wind protons. Despite the apparent redistribution the concentrations are still large in comparison with what would be expected from estimates of $\mathrm{H}$ diffusion coefficients in silicates, suggesting that diffusion rates are much lower in the heavily radiation-damaged regions and that the depth profile at depths greater than $500 \AA$ is a reflection of the density of radiation-produced 'traps' in the mineral lattices. In the amorphous layer above $\sim 500 \AA$, diffusion is rapid again, and the $\mathrm{H}$ concentration drops rapidly. It is quite clear that the physical and chemical properties of the outer micron are dominated by radiation damage effects.

The best evidence for surface deposits is the observation of S-rich coatings by Auger spectroscopy on Apollo 17 orange glass spheres [Grant et al., 1974]. This was a favorable case because the orange glass has had little if any solar wind ex- 


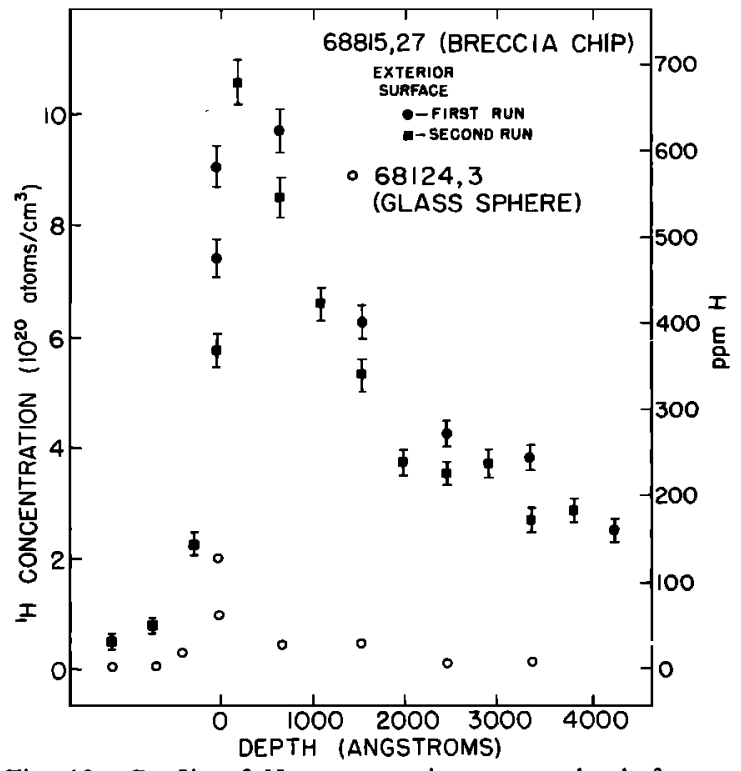

Fig. 13. Profile of $\mathbf{H}$ concentration versus depth from a lunar exterior piece of breccia 68815 [Leich et al., 1974], as determined with a nuclear resonant reaction technique. Depth resolution is $\sim 200 \AA$. Relatively large concentrations of solar wind $\mathrm{H}$ are observed down to depths many times larger than the solar wind implantation depth $(100-200 \AA)$. Much smaller amounts of $\mathbf{H}$ were found in the glass sphere, which had a very similar sampling history, indicating that the $\mathrm{H}$ in 68815 is lunar and not due to terrestrial $\mathrm{H}_{2} \mathrm{O}$.

posure. Similarly, ion probe studies have shown large amounts of $\mathrm{F}$ and $\mathrm{Cl}$ on the orange glass surfaces [Jovanovic and Reed, 1974]; however, these elements, particularly F, are sensitive to contamination, particularly from outgassing of mission packaging material [Leich et al., 1974]. Further (as was discussed in section B2), leaching [Tatsumoto et al., 1973] and volatilization [Silver, 1974] experiments are best interpreted as indicating that $\mathrm{Pb}$, rich in primordial ${ }^{204} \mathrm{~Pb}$, is concentrated on the surfaces of the spheres. For more typical soil samples, studies of volatile $\mathrm{Pb}$ provide the only strong suggestion of surface deposits. The best case is for 14163 [Silver, 1972], where $\sim 9 \%$ of the lead evolved at temperatures less than $600^{\circ}$. Moreover, this $\mathrm{Pb}$ showed a high ${ }^{207} \mathrm{~Pb} /{ }^{200} \mathrm{~Pb}$ ratio $(\sim 1.27)$, which could only be produced by decay of $U$ in the early history of the moon (before $4 \times 10^{\circ} \mathrm{yr}$ ago). The lowtemperature lead is required to be isolated from $U$ for the past $\sim 4 \times 10^{9} \mathrm{yr}$. This is most readily understood if the $\mathrm{Pb}$ is on the surface of the grains, consistent with its low release temperature. This is a somewhat startling result, given the opportunities for redistribution and mixing with more normal lunar $\mathrm{Pb}$ over $4 \times 10^{9} \mathrm{yr}$; however, it is consistent with the observation that the only volatile-rich lunar rocks from the highlands with ages of $3.85 \times 10^{9}$ yr or greater (section B2). It is very important to show whether this exotic lead is actually on the grain surfaces or perhaps resides in ultrafine, easily volatilized particles.

The presence of reimplanted atmospheric ions is best documented by the presence of ${ }^{40} \mathrm{Ar}$ in lunar soils greatly in excess of what could be produced by the decay of ${ }^{40} \mathrm{~K}$ in the soils over $4.5 \times 10^{\circ}$ yr [Heymann and Yaniv, 1970; Yaniv and Heymann, 1972]. Lunar soils show a totally unexpected correlation between ${ }^{40} \mathrm{Ar}$ and solar wind ${ }^{36} \mathrm{Ar}$. The ${ }^{30} \mathrm{Ar}$ was shown to reside on grain surfaces by an inverse dependence of the ${ }^{36} \mathrm{Ar}$ concentration on grain size and by etching experiments [Eberhardt et al., 1970]. The correlation indicates that the ex- cess ${ }^{40} \mathrm{Ar}$ is also on the grain surfaces. The ratio of (excess $\left.{ }^{10} \mathrm{Ar}\right) /{ }^{38} \mathrm{Ar}$ is highly variable in lunar soils and shows values (typically 1-2) that are many orders of magnitude higher than theoretical estimates of the solar ${ }^{40} \mathrm{Ar} /{ }^{30} \mathrm{Ar}$. Thus the excess ${ }^{40} \mathrm{Ar}$ is lunar in origin. The Apollo 17 surface mass spectrometer has detected ${ }^{40} \mathrm{Ar} /{ }^{36} \mathrm{Ar} \sim 10$ in the contemporary lunar atmosphere [Hodges and Hoffman, 1974]. The ${ }^{40} \mathrm{Ar}$ is released by slow diffusion and possibly by episodic events (impacts or lunar outgassing events [Hodges and Hoffman, 1974]). Once it is in the atmosphere, an ${ }^{40} \mathrm{Ar}$ atom is subject to ionization by solar wind ions or electrons and by solar $\mathrm{X}$ rays and then to acceleration by the solar wind electric field [Heymann and Yaniv, 1970; Manka and Michel, 1971; Bibring et al., 1974] to energies of $\sim 1 \mathrm{keV}$. Some of the ions will be accelerated away from the moon, but many will be implanted into the surface. Similarly, a solar wind atom that has diffused from the lunar soil into the atmosphere can be 'reimplanted' but at an energy much lower than that for the initial implantation. Thermal release studies have shown that similar release curves are observed for ${ }^{40} \mathrm{Ar}$ and ${ }^{36} \mathrm{Ar}$; this finding is surprising when one considers that the ${ }^{30} \mathrm{Ar}$ was presumably implanted at a much higher energy [Pepin et al., 1970; Frick et al., 1973]. Further, ${ }^{40} \mathrm{Ar}$ artificially implanted at $\sim 2 \mathrm{keV}$ into Apollo 15 green glass spheres was released at a much lower temperature $\left(\sim 300^{\circ} \mathrm{C}\right)$ than the natural ${ }^{40} \mathrm{Ar}$ in this or other soil samples $\left(\sim 700^{\circ}-\right.$ $800^{\circ} \mathrm{C}$ ) [Frick et al., 1973], leading to suggestions that atmospheric implantation could not account for the excess ${ }^{40} \mathrm{Ar}$. However, Frick et al. also showed that postimplantation heating could cause preferential loss of the implanted ${ }^{40} \mathrm{Ar}$ released at low temperatures, yielding released curves for the implanted ${ }^{40} \mathrm{Ar}$ qualitatively similar to those for the lunar ${ }^{\circ 0} \mathrm{Ar}$. Also, Bibring et al. [1974] obtained essentially the same release curves for $\mathrm{CO}$ for implantation energies corresponding to solar wind $C$ and to atmospherically accelerated $C$, provided that the surfaces had first been made amorphous by irradiation with high doses of $\mathrm{He}$ ions. This suggests that the distribution of both the implanted and the reimplanted ions is controlled by the properties of the surface, particularly the amorphous layer, rather than by the implantation energy. This is reasonable when one considers the results on the $\mathrm{H}$ distribution discussed above.

Many studies of the chemistry of lunar surface layers have focused on reduction processes in order to understand the submicron metallic iron grains found in lunar soils by magnetic studies. Housley et al. [1974] have proposed that the finegrained metal is formed by reduction of $\mathrm{FeO}$ by $\mathrm{H}$ in a soil sample during meteorite impact or by postimplantation reaction of solar wind hydrogen with oxidized iron, accompanied by diffusive loss of $\mathrm{H}_{2} \mathrm{O}$. Further evidence for metal produced by radiation is that metal particles from soils have $\mathrm{W}$ contents [Wlotzka et al., 1972, 1973] that are much larger than those for any type of meteoritic metal, although metal from an igneous fragment in 14321 also appeared to have a high W content. Tungsten behaves both as a lithophile and as a siderophile element; consequently, it is enriched in lunar rocks in comparison with other siderophile elements. Thus metal formed by reduction of lunar silicates would be expected to have high $W$, as is observed. Thus there is evidence that some larger metal fragments are formed by reduction, most likely by impact into $\mathrm{H}$ bearing soils. However, it is also possible that fine-grained metallic Fe on surfaces could also be formed directly during the implantation process or by postimplantation reduction without the necessity of impact heating or melting. Using photoelectron spectroscopy, Yin et al. [1975] have observed 
metallic Fe formed during He bombardment of olivine at solar wind energies, suggesting that reduction during implantation does occur, although the chemistry of the reduction process is not obvious for the case of He bombardment.

Estimates of solar wind sputtering rates for lunar material range from 0.05 [McDonnell and Flavill, 1974] to $0.5 \dot{A} / \mathrm{yr}$ [Bibring et al., 1974]. The sputtering is primarily due to $\mathrm{He}$ ions because of the trade off between increasing sputtering yields and decreasing abundances for heavier ions. The above rates are much smaller than surface-averaged erosion rates of lunar rocks $(\sim 10 \AA / \mathrm{yr})$ measured from profiles of solar flare produced radioactive nuclei [Imamura et al., 1974] or from galactic cosmic ray track profiles [Behrmann et al., 1973]. Micrometeorites appear to be the chief erosional mechanism for lunar rocks, but for individual grain surfaces, sputtering appears to be the dominant erosional mechanism. Erosion by very small particles (nanometeorites) has not received much attention. In addition to erosion it is possible that sputtering can produce some of the interesting isotopic properties that appear to be characteristic of lunar surface layers. Figure 14 shows the isotopic composition of oxygen released by partial reaction of lunar soils as a function of the amount of oxygen liberated [Epstein and Taylor, 1973]. If the initial reaction steps preferentially remove material from the surface layers of the grains, the amount removed corresponds to $\sim 50 \AA$. The first fractions show very high depletions in ${ }^{18} \mathrm{O}$ relative to ${ }^{18} \mathrm{O}$, which decrease rapidly toward typical bulk soil compositions as the surface layers are stripped away. Similar enrichments are observed for ${ }^{30} \mathrm{Si}$ with respect to ${ }^{89} \mathrm{Si}$. Also, lunar soils appear to have systematically higher ${ }^{41} \mathrm{~K} /{ }^{30} \mathrm{~K}$ [Barnes et al., 1973] and ${ }^{94} \mathrm{~S} /{ }^{22} \mathrm{~S}$ [Smith et al., 1973] ratios than lunar rock samples. However, the effects for $K$ and $S$ are $0.5-1 \%$ for a bulk sample and are surprisingly large in comparison with those observed for $\mathrm{O}$ and $\mathrm{Si}$ if they are due entirely to the surface layers.
Further, a leaching experiment gave a ${ }^{30} \mathrm{~K} /{ }^{\mathbf{1 1}} \mathrm{K}$ ratio that was indistinguishable from the bulk soil, suggesting that the $K$ isotopic variations are not a surface property; this is quite surprising in light of the $\mathrm{O}$ and $\mathrm{Si}$ results. Sputtering is only one possible explanation for the $\mathrm{O}$ and $\mathrm{Si}$ isotopic variations. Clayton et al. [1974] reject sputtering and prefer to ascribe the isotopic variations to vapor deposition and preferential loss of light elements in the lunar atmosphere.

Accretionary particles are very important lunar surface features, as is shown by dark surface coatings (patinas) of these on many rock surfaces [Blanford et al, 1974]. These are small, impact-produced, disk-shaped glass splashes of micron to submicron size that are formed in high abundance on many soil particles as well as on rock surfaces. They appear to be very fluid, and formation temperatures of $1300^{\circ}-1700^{\circ} \mathrm{C}$ are estimated. These particles are to a certain extent a complication, because most of the interesting volatile elements are probably outgassed in the accretionary particle; thus they form a patch of fresh glassy surface and bury an older implanted surface in the process. Their presence leads to chemical and physical surface heterogeneities and complicates the interpretation of thermal release as well as many other 'traditional' experiments. It is just as well that these are cute little beasts, because we are going to have to learn to live with them. An interesting possibility put forward by Blanford et al. is that the highly outgassed accretionary particles could be the source of the observed $\mathrm{O}$ and $\mathrm{Si}$ surface isotopic variations.

In summary, the lunar surface layers at least are the site of very interesting processes and at best may represent a fundamentally different state of matter than has hitherto been available for study. It is also likely that similar radiationdamaged, implanted, amorphous material must characterize interstellar dust grains and possibly the grains that once populated our solar nebula at the beginning of the solar system. It

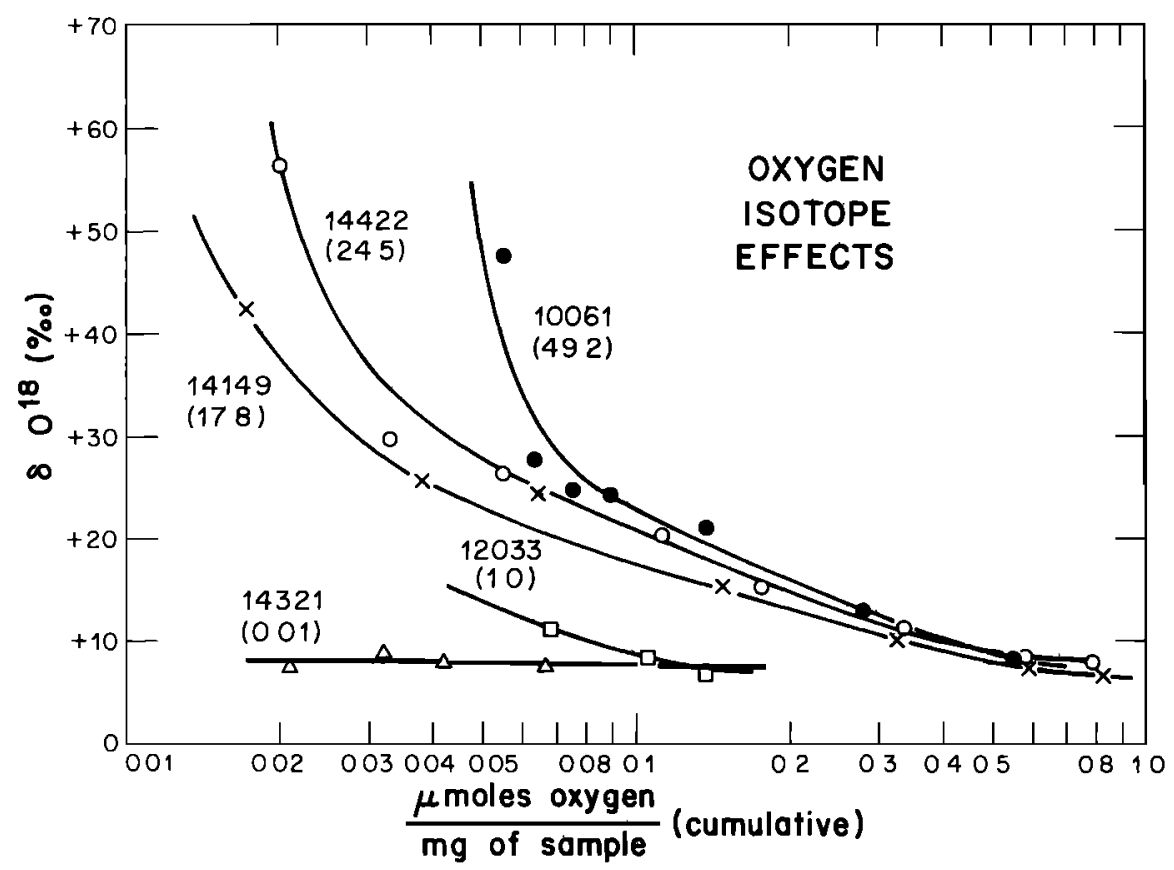

Fig. 14. Variation of oxygen isotopic composition during partial reaction studies of lunar soils [Epstein and Taylor, 1973] as a function of the cumulative amount of oxygen released. The $\delta^{10} \mathrm{O}$ gives the fractional increase in the ${ }^{18} \mathrm{O} /{ }^{10} \mathrm{O}$ ratio relative to that for ocean water, expressed in parts per thousand. The initial fractions, corresponding to the reaction of surface layers, are highly enriched in ${ }^{10} \mathrm{O}$. Sample 14321 is an interior rock fragment demonstrating that the isotopic enrichments are related to lunar surface exposure. 
is also of interest to compare the properties of lunar surface layers with materials that are radiation damaged under laboratory conditions or conditions prevailing in the interiors of proposed fission and fusion reactors. I would argue that there are important problems as well as interesting science associated with the study of the outer lunar micron.

\section{Microcraters}

I find it difficult to explain to students why small, $\lesssim 1-\mathrm{cm}$ sized glass-lined impact pits on rocks were unexpected. Presumably, it was believed that impacts of microgram-sized particles would produce fracturing and spallation of rock surfaces without leaving visible craters. In any case, impact pits are now an accepted commonplace feature of lunar rocks and are discussed in detail in several reviews [Neukum et al., 1973; Hörz et al., 1975]. A crater of 0.05- to 1$\mathrm{mm}$ pit diameter is characterized by a central pit with a depth to diameter ratio of $\sim 0.7$ [Brownlee et al, 1973], which is much larger than that for meter- or kilometer-sized craters. The central pit corresponds to material ejected from the immediate vicinity of the point of impact, possibly much of it being volatilized. This includes the projectile; no residues can be found in the bottom of the pits that can unambiguously be attributed to the micrometeorite producing the pit [Schneider et al., 1973]. The central pit is lined by a cup of glass with some evidence of flow at the margins. At greater distances from the point of impact there is insufficient energy imparted to the host material to cause melting but enough to cause mechanical displacement, leading to the formation of a distinctive 'spall zone,' characterized by an intersecting pattern of radial and concentric fractures. The ratio of spall to pit diameters is typically 4 . For craters smaller than $1-5 \mu \mathrm{m}$ the spall zone is absent, and identification becomes more difficult [Neukum et al., 1972]. The observed microcraters are interpreted as being of 'primary' origin rather than as being produced by high-velocity ejecta from larger impacts ('secondary'). The arguments for this are as follows:

1. In the required velocity range the flux of primary particles is many orders of magnitude higher than the flux of secondaries.

2. High-velocity secondary particles are preferentially emitted at low angles with respect to the lunar surface; thus microcraters from secondary particles should be concentrated on vertical faces of rocks rather than on horizontal surfaces, contrary to what is observed [Hartung et al., 1972].

These arguments may not be valid for micron and submicron craters. Figure 15 shows a composite crater frequency distribution compiled from data on several rocks and the corresponding mass of micrometeorites in a given pit diameter range. Most of the micrometeorite mass infall to the moon comes in microgram particles.

Quantitative measurements of crater densities are complicated by saturation effects in which recent craters obliterate earlier ones, tending to make the measured crater densities low. A wide range in crater densities is observed [Neukum et al., 1973]; this range may reflect either a gradual transition to steady state crater densities [Hörz et al., 1975] or differences in the mechanical properties of the host rocks. Micrometeorite flux estimates have been made by combining crater densities for lightly cratered rocks ('production surfaces') with surface residence times calculated from galactic cosmic ray track densities. However, the track surface residence times in many cases are model ages, and only limits on the crater production rate are obtained [Crozaz et al., 1974]. Despite the complica-

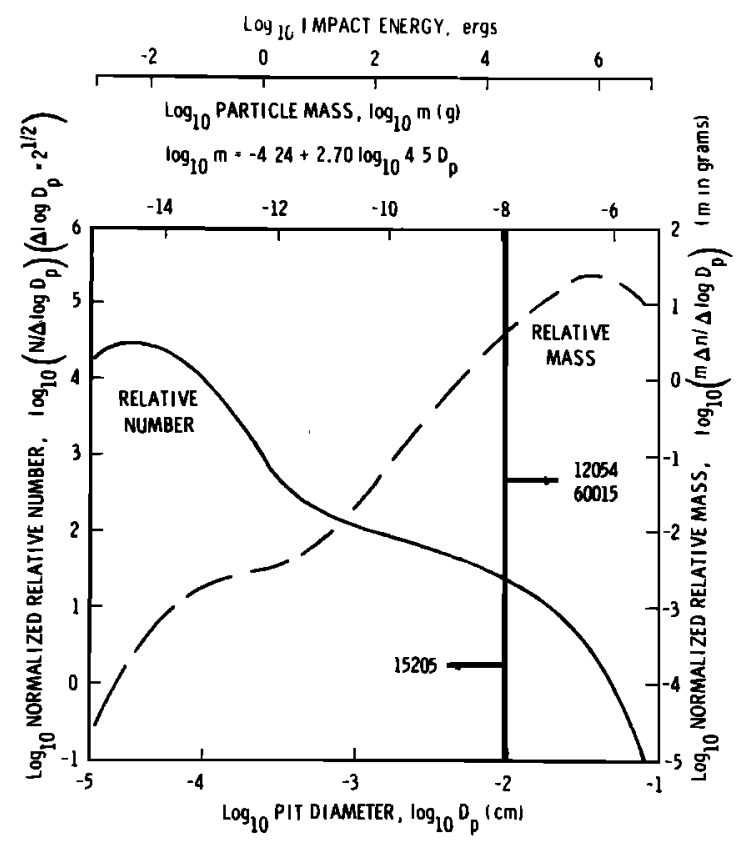

Fig. 15. Relative frequency by number (solid curve) of microimpact pits as a function of the pit diameter $D p$ for logarithmic pit diameter intervals corresponding to a factor of $2^{1 / 2}$ and the corresponding relative mass of micrometeorites in the same log pit diameter intervals [Hörz et al., 1975]. The frequency curve is a composite of data from several rocks. The scaling relations from pit diameter to impacting particle mass and energy are indicated. Most of the mass infall to the moon is in the form of microgram particles.

tions it appears that the microimpact rate averaged over $\sim 10^{\circ}$ $y r$, as determined from crater densities, is $\sim 10$ times higher than that calculated from measurement of the present-day micrometeorite flux. However, there are indications [Hörz et al., 1975] that the present-day flux estimates are too high, because they do not allow for anisotropies in the micrometeorite flux. A higher flux in the past has been obtained by the independent technique of dating individual microcraters by using solar flare heavy ion tracks in the glass lining of the pit [Hartung and Storzer, 1974]. The results are somewhat complicated by the necessity of applying large annealing corrections to the tracks in the glass; however, this appears to be a very profitable area for further research.

\section{Enhanced Iron Emission in Solar Flares}

The purpose of this section is to illustrate further the use of lunar samples and of terrestrial materials exposed in the lunar environment as detectors of particles from the interplanetary medium, the sun, and the galaxy. The preceding discussion of the use of microcrater densities to determine the long-term micrometeorite flux was one example. The present discussion concerns a result of great importance for cosmic ray physics and for the determination of solar system elemental abundances.

The most valuable artifact from Surveyor 3 returned by Apollo 12 was a filter from the TV camera, which because of 2.5-yr exposure to solar flares contained readily measurable densities of particle tracks (Figure 16) from the Fe group nuclei in the flares [Price et al., 1971]. As is illustrated in Figure 16, the track densities were greatly in excess of those calculated by using satellite solar flare He fluxes during the same period and by assuming that the $\mathrm{Fe} / \mathrm{He}$ ratio in the flares was the same as that in the solar photosphere. Also, larger 


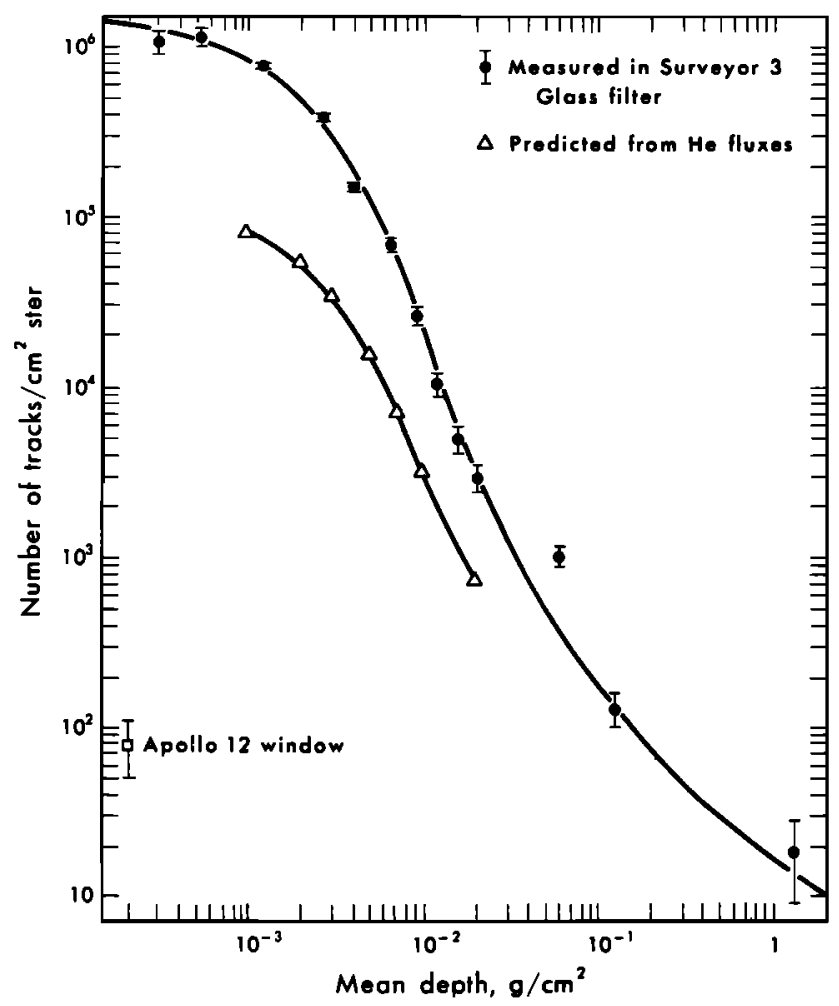

Fig. 16. Measured densities of solar flare Fe tracks penetrating to a given depth in Surveyor 3 glass compared with predicted track density based on satellite $\mathrm{He}$ fluxes. This was the first evidence that heavy elements were preferentially accelerated in solar flares.

enhancements were observed at lower energies (shallower depths). This was subsequently confirmed by plastic track detectors flown on the Apollo 16 cosmic ray experiment [Braddy et al., 1973; Fleischer and Hart, 1973], which were exposed to the April 16, 1972, flare, and similarly by low-energy particles detected in plastics on the Apollo 17 cosmic ray package (R. T. Woods et al., unpublished manuscript, 1974), even though no visible flare activity occurred during Apollo 17. The Surveyor glass conclusions were further verified by detectors on satellites [Mogro-Campero and Simpson, 1972], which also showed that there is a systematic increase in the heavy element overabundance with increasing mass, demonstrating preferential acceleration of heavy nuclei in solar flares. Previously, it had been assumed that nuclei with the same nuclear charge to mass ratio would not be fractionated during acceleration and that the relative intensities of solar flare ions could be used to obtain refined values for solar abundances [Biswas and Fichtel, 1965]. The preferential acceleration of heavy nuclei is believed to show that during the early stages of acceleration the atomic charge is less than the nuclear charge; thus $\mathrm{Fe}$ and $\mathrm{He}$ are differentially accelerated. One possible mechanism is that the source region contains a much higher fraction of ionized $\mathrm{Fe}$ and other heavy elements than $\mathrm{He}$ and the $\mathrm{Fe}$ is preferentially extracted [Hirschberg, 1973]. Independent of the detailed explanation, it is now clear that much care is necessary in deducing solar abundances from relative intensities of solar flare ions.

\section{Epilog}

In the preceding section, I have summarized a few of the exciting and unexpected results that were obtained from the Apollo program. The choice of topics is clearly personal. Some of these results, e.g., the solar flare Fe enhancements, are now widely accepted and essentially established facts. Others, like the study of impact breccias and microcraters, are now mature fields of study with well-established bodies of data. In contrast, topics like the study of the regolith and the outer micron are immature research areas from which much is yet to be learned. Finally, results such as the ancient lunar magnetic field and the early intense bombardment have implications far beyond lunar science and when they are understood, will reshape our view of the solar system as a whole.

My conclusion is that lunar science, both past and future, and the carefully protected lunar rocks are the true legacies of the Apollo program. Hopefully, less biased historians of the future will concur.

Acknowledgments. I acknowledge years of profitable discussions with my Caltech colleagues, particularly G. J. Wasserburg, and with the members of the Lunar Sample Analysis Planning Team during Apollo 15, 16, and 17. This paper was prepared with financial support from NASA grant NAS 07023 and with a tremendous effort on the part of Jeanne Grinols. Contribution 2582 of the Division of Geological and Planetary Sciences, California Institute of Technology.

\section{BIBLIOGRAPHY}

Because of the large number of references to the Lunar Science Conference proceedings we have adopted an abbreviation for the conference number and volume in order to save space. The first digit after the prefix $L S C$ refers to the conference, and the second digit to the volume. For example, $L S C 3-I$ refers to volume 1 of Proceedings of the Third Lunar Science Conference. The Apollo 12 and Third Conference proceedings were published by MIT Press. The other proceedings were published by Pergamon Press.

Adler, I., J. I. Trombka, R. Schmadebeck, P. Lowman, H. Blodget, L. Yin, E. Eller, M. Podwysocki, J. R. Weidner, A. L. Bickel, R. K. L. Lum, J. Gerard, P. Gorenstein, P. Bjorkholm, and B. Harris Results of the Apollo 15 and $16 \mathrm{X}$-ray experiment. LSC4-3, 27832792, 1973.

Ahrens, L., The Distribution of Elements in Our Planet, McGraw-Hill, New York, 1965.

Albee, A. L., and A. A. Chodos, Microprobe investigations on Apollo 11 samples, $L S C l-1,135-159,1970$.

Albee, A. L., A. A. Chodos, R. F. Dymek, A. J. Gancarz, D. S. Goldman, D. A. Papanastassiou, and G. J. Wasserburg, Dunite from the lunar highlands: Petrography, deformational history, RbSr age, Lunar Sci. 5, pp. 3-5, Lunar Sci Inst., Houston, Tex., 1974.

Anders, E., How well do we know 'cosmic' abundances?, Geochim. Cosmochim. Acta, 35, 516-522, 1971.

Anders, E., R. Ganapathy, R. R. Keays, J. C. Laul, and J. W. Morgan, Volatile and siderophile elements in lunar rocks: Comparison with terrestrial and meteoritic basalts, LSC2-2, 1021-1036, 1971.

Anderson, D. L., Composition and origin of the moon, Earth Planet. Sci. Lett., 18, 301-316, 1973a.

Anderson, D. L., Removal of a constraint on the composition of the lunar interior, J. Geophys. Res., 78, 3222, $1973 b$.

Anderson, D. L., and R. L. Kovach, The lunar interior, Phys. Earth Planet. Interiors, 6, 116-122, 1972.

Arrhenius, G., S. Laing, D. MacDougall, L. Wilkening, N. Bhandari, S. Bhat, D. Lal, G. Rajagopalan, A. S. Tamhane, and V. S. Venkatavaradan, The exposure history of the Apollo 12 regolith, LSC2-3, 2583-2598, 1971 .

Baedecker, P. A., R. Schaudy, J. L. Elzie, J. Kimberlin, and J. T. Wasson, Trace element studies of rocks and soils from Oceanus Procellarum and Mare Tranquillitatis, LSC2-2, 1037-1061, 1971.

Baedecker, P. A., C. L. Chou, L. L. Sundberg, and J. T. Wasson, Volatile and siderophilic trace elements in the soils and rocks of Taurus-Littrow, LSC5-2, 1625-1644, 1974.

Barnes, I. L., E. L. Garner, J. W. Gramilich, L. A. Machlan, J. R. Moody, L. J. Moor, T. J. Murphy, and W. R. Shields, Isotopic abundance ratios and concentrations of selected elements in some Apollo 15 and Apollo 16 samples, LSC4-2, 1197-1208, 1973.

Behrmann, C., G. Crozaz, R. Drozd, C. Hohenberg, C. Ralston, R. Walker, and D. Yuhas, Cosmic-ray exposure history of North Ray and South Ray material, LSC4-2, 1957-1974, 1973. 
Bibring, J. P., A. L. Burlingame, J. Chaumont, Y. Langevin, M. Maurette, and P. C. Wszolek, Simulation of lunar carbon chemistry, 1, 2, Solar wind contribution, LSC5-2, 1747-1762, $1763-1784,1974$.

Biswas, S., and C. E. Fichtel, Energetic particles from the sun, Space Sci. Rev., 4, 709, 1965.

Blanford, G. E., R. M. Fruland, D. S. McKay, and D. A. Morrison, Lunar surface phenomena: Solar flare track gradients, microcraters, and accretionary particles, LSC 5-3, 2501-2526, 1974.

Bogard, D. D., L. E. Nyquist, W. C. Hirsch, and D. R. Moore, Trapped solar and cosmogenic noble gas abundances in Apollo 15 and 16 deep drill samples, Earth Planet. Sci. Lett., 21, 52-69, 1973.

Bogard, D. D., L. E. Nyquist, B. M. Bansal, and H. Wiesmann, An old lunar rock?, Lunar Sci. 5, pp. 70-72, Lunar Sci. Inst., Houston, Tex., 1974.

Borg, J., M. Maurette, L. Durrieu, and C. Jouret, Ultramicroscopic features in micron-sized lunar dust grains and cosmophysics, LSC23. 2027-2040, 1971.

Boyce, J. M., A. L. Dial, and L. A. Soderblom, Ages of the lunar nearside light plains and maria, LSC5-1, 11-24, 1974.

Braddy, D., J. Chan, and P. B. Price, Charge states and energydependent composition of solar flare particles, Phys. Rev. Lett., 30, 669-671, 1973.

Brecher, A., W. H. Menke, and K. R. Morash, Comparative magnetic studies of some Apollo 17 rocks and soils and their implications, LSC5-3, 2795-2814, 1974.

Brett, R., A lunar core of Fe-Ni-S, Geochim. Cosmochim. Acta, 37, 165-169, 1973.

Brownlee, D. E., F. Hörz, J. F. Vedder, D. E. Gault, and J. B. Hartung. Some physical parameters of micrometeoroids, LSC4-3, 3197-3212, 1973.

Burnett, D. S., and D. S. Woolum, Lunar neutron capture as a tracer for regolith dynamics, LSC5.2, 2061-2074, 1974.

Burnett, D. S., J. C. Huneke, F. A. Podosek, G. P. Russ III, and G. J. Wasserburg, The irradiation history of lunar samples, LSC2-2, 1671-1679, 1971a.

Burnett, D. S., M. Monnin, M. Seitz, R. Walker, and D. Yuhas, Lunar astrology-U-Th distributions and fission-track dating of lunar samples, $L S C 2-2,1503-1520,1971 b$.

Cadogan, P. H., G. Eglinton, J. N. M. Firth, J. R. Maxwell, J. B. Mays, and C. T. Pillinger, Survey of lunar carbon compounds, 2 , The carbon chemistry of Apollo 11, 12, 14, and 15 samples, LSC3-2, 2069-2090, 1972.

Chao, E. C. T., J. A. Minkin, and J. B. Best, Apollo 14 breccias: General characteristics and classification, LSC3-1, 645-661, 1972.

Cisowski, C. S., J. R. Dunn, M. Fuller, M. F. Rose, and P. J. Wasilewski, Impact processes and lunar magnetism, LSCS-3, 2841-2858, 1974.

Clayton, R. N., T. K. Mayeda, and J. M. Hurd, Loss of oxygen, silicon, sulfur, and potassium from the lunar regolith, LSC5-2, 1801-1810, 1974.

Crozaz, G., R. Drozd, C. Hohenberg, C. Morgan, C. Ralston, R. Walker, and D. Yuhas, Lunar surface dynamics: Some general conclusions and new results from Apollo 16 and 17, LSC5-3, 2475-2500, 1974.

Curtis, D., and G. J. Wasserburg, Apollo 17 neutron stratigraphy; Sedimentation and mixing in the lunar regolith, in Proceedings of Lunar Regolith Conference, Lunar Science Institute, Houston, Tex., in press, 1975.

DesMarais, D. J., J. M. Hayes, and W. G. Meinschein, The distribution in lunar soil of carbon released by pyrolysis, LSC4-2, 1543-1558, 1973.

Drake, M. J., I. S. McCallum, G. A. McKay, and D. F. Weill, Mineralogy and petrology of Apollo 12 sample no. 12013: A progress report, Earth Planet. Sci. Lett., 9, 103-123, 1970.

Duncan, A. R., A. J. Erlank, J. P. Willis, M. K. Sher, and L. H. Ahrens, Trace element evidence for a two-stage origin of some titaniferous mare basalts, $L S C 5-2,1147-1158,1974$.

Dyal, P., C. W. Parkin, and W. D. Daily, Surface magnetometer experiments: Internal lunar properties, LSC4-3, 2229, 1973.

Dyal, P., C. W. Parkin, and W. D. Daily, Magnetism and the interior of the moon, Rev. Geophys. Space Phys., 12, 568-591, 1974a.

Dyal, P., C. W. Parkin, and W. D. Daily, Temperature and electrical conductivity of the lunar interior from magnetic transient measure. ments in the geomagnetic tail, LSC5-3, 3059-3072, $1974 b$.

Eberhardt, P., J. Geiss, H. Graf, N. Grögler, U. Krăhenbühl, H. Schwaller, J. Schwarzmuller, and A. Stettler, Trapped solar wind noble gases, exposure age and K/Ar-age in Apollo 11 lunar fine material, $L S C l-2,1037-1070,1970$.
Eberhardt, P., J. Geiss, H. Graf, N. Grögler, M. D. Mendia, M. Mörgeli, H. Schwaller, and A. Stettler, Trapped solar wind noble gases in Apollo 12 lunar fines 12001 and Apollo 11 breccia 10046, LSC3-2, 1821-1856, 1972.

Eberhardt, P., O. Eugster, J. Geiss, H. Graf, N. Grögler, S. Guggisberg, M. Jungck, P. Maurer, M. Mörgeli, and A. Stettler, Solar wind and cosmic radiation history of Taurus-Littrow regolith, Lunar Sci. 5, pp. 197-199, Lunar Sci. Inst., Houston, Tex., 1974.

Ehmann, W. D., and L. L. Chyi, Abundances of the group IVB elements, $\mathrm{Ti}, \mathrm{Zr}$, and $\mathrm{Hf}$ and implications of their ratios in lunar materials, LSC5-2, 1015-1025, 1974.

Eldridge, J. S., G. D. O'Kelley, and K. J. Northcutt, Primordial radioelement concentrations in rocks and soils from TaurusLittrow, LSC5-2, 1025-1035, 1974.

El Goresy, A., P. Ramdohr, and O. Medenbach, Lunar samples from Descartes site: Opaque mineralogy and geochemistry, LSC4-1, 733-750, 1973.

Epstein, S., and H. P. Taylor, Jr., The isotopic composition and concentration of water, hydrogen, and carbon in some Apollo 15 and 16 soils and in the Apollo 17 orange soil, LSC4-2, 1559-1576, 1973.

Epstein, S., and H. P. Taylor, Jr., D/H and ${ }^{18} \mathrm{O} /{ }^{10} \mathrm{O}$ ratios of $\mathrm{H}_{2} \mathrm{O}$ in the 'rusty' breccia 66095 and the origin of 'lunar water,' LSC5-2, 1939-1955, 1974.

Eugster, O., F. Tera, D. S. Burnett, and G. J. Wasserburg, The isotopic composition of $\mathrm{Gd}$ and the neutron capture effects in samples from Apollo 11, Earth Planet. Sci. Lett., 8, 20-30, 1970.

Fleischer, R. L., and H. R. Hart, Jr., Enrichment of heavy nuclei in the 17 A pril, 1972 solar flare, Phys. Rev. Lett., 30, 31, 1973.

Fleischer, R. L., H. R. Hart, Jr., and W. R. Giard, Surface history of lunar soil and soil columns, Geochim. Cosmochim. Acta, 38, 365-380, 1971.

Frick, U., H. Baur, H. Funk, D. Phinney, C. Schäfer, L. Schultz, and P. Signer, Diffusion properties of light noble gases in lunar fines, LSC4-2, 1987-2002, 1973.

Fuller, M., Lunar magnetism, Rev. Geophys. Space Phys., 12, 23, 1974.

Ganapathy, R., and E. Anders, Bulk compositions of the moon and earth estimated from meteorites, LSC5-2, 1181-1206, 1974.

Ganapathy, R., R. R. Keays, J. C. Laul, and E. Anders, Trace elements in Apollo 11 lunar rocks: Implications for meteorite influx and origin of moon, $L S C 1-2,1117-1142,1970$.

Ganapathy, R., J. W. Morgan, U. Krähenbühl, and E. Anders, Ancient meteoritic components in lunar highland rocks: Clues from trace elements in Apollo 15 and 16 samples, LSC4-2, 1239-1262, 1973.

Gault, D. E., F. Hörz, D. E. Brownlee, and J. B. Hartung, Mixing of the lunar regolith, LSC 5-3, 2365-2386, 1974.

Geiss, J., Solar wind compositions and implications about the history of the solar system, Proc. Int. Conf. Cosmic Rays 13th, 5, 3375$3398,1973$.

Goldberg, R. H., D. S. Burnett, M. J. Furst, and T. Tombrello, Fluorine concentrations in carbonaceous chondrites (abstract), Bull. Amer. Phys. Soc., 20, 32, 1975.

Gose, W. A., D. W. Strangway, and G. W. Pearce, A determination of the intensity of the ancient lunar magnetic field, Moon, 7, 197$200,1973$.

Grant, R. W., R. M. Housley, F. J. Szalkowski, and H. L. Marcus, Auger electron spectroscopy of lunar samples, LSC5-3, 2423-2440, 1974.

Green, D. H., A. E. Ringwood, N. G. Ware, W. O. Hibberson, A. Major, and E. Kiss, Experimental petrology and petrogenesis of Apollo 12 basalts, $L S C 2-1,601-616,1971$.

Grossman, L., R. N. Clayton, and T. K. Mayeda, Oxygen isotopic constraints of the moon, LSC5-2, 1207-1212, 1974

Haggerty, S. E., Armalcolite and genetically associated opaque minerals in the lunar samples, LSC4-1, 777-798, 1973.

Hanks, T. C., and D. L. Anderson, The early thermal history of the earth, Phys. Earth Planet. Interiors, 2, 19-29, 1968.

Hartung, J. B., and D. Storzer, Lunar microcraters and their solar flare track record, LSC 5-3, 2527-2542, 1974.

Hartung, J. B., F. Hörz, and D. E. Gault, Lunar microcraters and interplanetary dust, $L S C 3-3,2735-2753,1972$.

Haskin, L. A., C. Y. Shih, B. M. Bansal, J. M. Rhodes, H. Wiesmann, and L. E. Nyquist, Chemical evidence for the origin of 76535 as a cumulate, LSC5-2, 1213-1226, 1974.

Hays, J. F., and D. Walker, Lunar igneous rocks and the nature of the lunar interior, in Proceedings of Soviet-American Conference on Cosmochemistry of the Moon and Planets, edited by J. H. Pomeroy, NASA, in press, 1975. 
Head, J. W., Lunar dark-mantle deposits: Possible clues to the distribution of early mare deposits, LSC5-1, 207-222, 1974.

Heymann, D., and A. Yaniv, $A r^{\circ 0}$ anomaly in samples from Tranquillity base, $L S C I-2,1261-1267,1970$.

Hintenberger, H., H. W. Weber, and L. Schultz, Solar, spallogenic, and radiogenic rare gases in Apollo 17 soild and breccias, LSC5-2, 2005-2022, 1974.

Hirschberg, J., Helium abundance of the sun, Rev. Geophys. Space Phys., II, 115-131, 1973.

Hodges, R. R., Jr., and J. H. Hoffman, Episodic release of ${ }^{40} \mathrm{Ar}$ from the interior of the moon, LSC5-3, 2955-2962, 1974.

Hörz, F., D. A. Morrison, D. E. Gault, V. R. Oberbeck, W. L. Quaide, J. F. Vedder, D. E. Brownlee, and J. B. Hartung, The micrometeoroid complex and evolution of the lunar regolith, in Proceedings of the Soviet-American Conference on Cosmochemistry of the Moon and Planets, edited by J. H. Pomeroy, NASA, in press, 1975.

Housley, R. M., E. H. Cirlin, N. E. Paton, and 1. B. Goldberg, Solar wind and micrometeorite alteration of the lunar regolith, LSC 5-3. 2623-2642, 1974

Howard, K. A., D. E. Wilhelms, and D. H. Scott, Lunar basin formation and highland stratigraphy, Rev. Geophys. Space Phys., 12, 309-328, 1974.

Huneke, J. C., E. K. Jessberger, F. A. Podosek, and G. J. W asserburg, ${ }^{40} \mathrm{Ar} /{ }^{39} \mathrm{Ar}$ measurements and the chronology of metamorphic and volcanic activity in the Taurus-Littrow region, LSC4-2, 1725-1756, 1973.

Husain, L., and O. A. Schaeffer, Lunar evolution: The first 600 million years, Geophys. Res. Lett., 2, 29-33, 1975.

Hutcheon, I. D., P. P. Phakey, and P. B. Price, Studies bearing on the history of lunar breccias, LSC3-3, 2845-2866, 1972.

Imamura, M., K. Nishizumi, M. Honda, R. C. Finkel, J. R. Arnold, and C. P. Kohl, Depth profiles of ${ }^{\text {ss }} \mathrm{Mn}$ in lunar rocks and soils, LSC5-2, 2093-2104, 1974.

James, O. B., Lunar highlands breccias generated by major impacts, in Proceedings of the Soviet-American Conference on the Cosmochemistry of the Moon and Planets, edited by J. H. Pomeroy, NASA, in press, 1975.

Jovanovic, S., and G. W. Reed, Labile and non labile element relationships among Apollo 17 samples, LSC5-2, 1659-1684, 1974.

Kirsten, T., O. Müller, F. Steinbrunn, and J. Zähringer, Study of distribution and variations of rare gases in lunar material by a microprobe technique, $L S C l-2,1331-1343,1970$.

Kothari, B. K., and P. S. Goel, Nitrogen in lunar samples, LSC4-2, $1587-1596,1973$.

Kovach, R. L., and D. L. Anderson, The interiors of the terrestrial planets, $J$. Geophys. Res., 70, 2873-2882, 1965.

Krähenbühl, U., R. Ganapathy, J. W. Morgan, and E. Anders, LSC42, 1325-1349, 1973.

Lammlein, D. R., G. V. Latham, J. Dorman, Y. Nakamura, and M. Ewing, Lunar seismicity and tectonics, Rev. Geophys. Space. Phys., 12. 1-22, 1974

Langseth, M. G., J. L. Chute, and S. Keihm, Direct measurements of heat flow from the moon, Lunar Sci. 4, pp. 455-456, Lunar Sci. Inst., Houston, Tex., 1973.

Latham, G., J. Dorman, F. Duennebier, M. Ewing, D. Lammlein, and $Y$. Nakamura, Moonquakes, meteoroids, and the state of the lunar interior, $L S C 4-3,2515-2528,1973$.

Leich, D. A., R. H. Goldberg, D. S. Burnett, and T. A. Tombrello, Hydrogen and fluorine in the surfaces of lunar samples, LSC5-2, 1869-1884, 1974.

Lightner, B. D., and K. Marti, Lunar trapped xenon, LSC5-2, 2023-2032, 1974

Lunatic Asylum, Mineralogic and isotopic investigations on lunar rock 12013, Earth Planet. Sci. Lett. 9, 137-163, 1970.

MacDougall, D., R. S. Rajan, I. D. Hutcheon, and P. B. Price, Irradiation history and accretionary processes in lunar and meteoritic breccias, LSC4-3, 2319-2336, 1973.

Manka, R. H., and F. C. Michel, Lunar atmosphere as a source of lunar surface elements, $L S C 2-2,1717-1728,1971$.

Manson, V., Geochemistry of basaltic rocks: Major elements, in Basalts, edited by H. H. Hess and A. Poldervaart, pp. 215-270, Interscience, New York, 1967.

Maurette, M., and P. B. Price, Electron microscopy of irradiation effects in space, Science, 187, 121-129, 1975.

McDonnell, J. A. M., and R. P. Flavill, Solar wind sputtering on the lunar surface: Equilibrium crater densities related to past and present microparticle influx rates, LSC5-3, 2441-2450, 1974.

Metzger, A. E., J. I. Trombka, R. C. Reedy, and J. R. Arnold, Ele- ment concentrations from lunar orbital gamma-ray measurements, LSC5-2, 1067-1079, 1974

Meyer, C., R. Brett, N. J. Hubbard, D. A. Morrison, D. S. McKay, F. K. Aitken, H. Takeda, and E. Shonfeld, Mineralogy, chemistry and origin of the Kreep in soil samples from the Ocean of Storms, LSC2-1, 393-411, 1971 .

Mizutani, H., and M. Osako, Elastic-wave velocities and thermal diffusivities of the Apollo 17 rocks and their geophysical implications, LSC5-3, 2891-2902, 1974.

Mogro-Campero, A., and J. A. Simpson, Abundances of solar accelerated nuclei from carbon to iron, Astrophys. J. Lett., 137, L37-L44, 1972.

Moore, C. B., C. F. Lewis, and J. D. Cripe, Total carbon and sulfur contents of Apollo 17 lunar samples, LSC5-2, 1897-1906, 1974.

Morgan, J. W., U. Krähenbühl, R. Ganapathy, and E. Anders, Trace elements in Apollo 15 samples: Implications for meteorite influx and volatile depletion on the moon, LSC3-2, 1361-1376, 1972.

Morgan, J. W., R. Ganapathy, H. Higuchi, U. Krähenbühl, and E. Anders, Lunar basins: Tentative characterization of projectiles, from meteoritic elements in Apollo 17 boulders, LSC5-2, 1703-1736, 1974.

Morgan, J. W., R. Ganapathy, H. Higuchi, and E. Anders, Meteoritic material on the moon, in Proceedings of the Soviet-American Conference on the Cosmochemistry of the Moon and Planets, edited by J. H. Pomeroy, NASA, in press, 1975.

Nakamura, Y., G. Latham, D. Lammlein, M. Ewing, F. Duennebier, and J. Dorman, Deep lunar interior inferred from, recent seismic data, Geophys. Res. Lett., I, 137-140, 1974a.

Nakamura, Y., J. Dorman, F. Duennebier, M. Ewing, D. Lammlein, and G. Latham, High-frequency lunar teleseismic events, $L S C 5$-3, 2883-2891, 1974b.

Neukum, G., E. Schneider, A. Mehl, D. Störzer, G. A. Wagner, H. Fechtig, and M. R. Block, Lunar craters and exposure ages derived from crater statistics and solar flare tracks, LSC3-3, 2793-2810, 1972.

Neukum, G., F. Hörz, D. A. Morrison, and J. B. Hartung, Crater populations on lunar rocks, LSC4-3, 3255-3276, 1973.

Nunes, P. D., and M. Tatsumoto, Excess lead in 'rusty rock,' 66095, Science, 182, 916-919, 1973.

Papanastassiou, D. A., and G. J. Wasserburg, Lunar chronology and evolution from Rb-Sr studies of Apollo 11 and 12 samples, Earth Planet. Sci. Lett., 11, 37, 1971.

Papanastassiou, D. A., and G. J. Wasserburg, Rb-Sr systematics of Luna 20 and Apollo 16 samples, Earth Planet. Sci. Lett., 17, 52-63, $1972 a$.

Papanastassiou, D. A., and G. J. Wasserburg, The Rb-Sr age of a crystalline rock from Apollo 16, Earth Planet. Sci. Lett., 16, 289, $1972 b$.

Papanastassiou, D. A., G. J. Wasserburg, and D. S. Burnett, Rb-Sr ages of lunar rocks from the Sea of Tranquillity, Earth Planet. Sci. Lett., 8, 1, 1970.

Papike, J. J., A. E. Bence, and D. H. Lindsley, Mare basalts from the Taurus-Littrow region of the moon, LSC5-1, 471-504, 1974.

Patterson, J. H., A. L. Turkevich, E. J. Franzgrote, T. E. Economou, and K. P. Sowinski, Chemical composition of the lunar surface in a terra region near the crater Tycho, Science, 168, 825-828, 1970.

Pearce, G. W., D. W. Strangway, and W. A. Gose, Remanent magnetization of the lunar surface, LSC3-3, 2449-2464, 1972.

Pepin, R. O., L. E. Nyquist, D. Phinney, and D. C. Black, Rare gases in Apollo 11 lunar material, $L S C 1-2,1435-1444,1970$.

Philpotts, J. A., C. C. Schnetzler, D. F. Nava, M. L. Bottino, P. D. Fullagar, H. H. Thomas, S. Schumann, and C. W. Kouns, Apollo 14: Some geochemical aspects, LSC3-2, 1293-1305, 1972.

Phinney, W. C., J. L. Warner, and C. H. Simonds, Lunar highland rock types: Their implications for impact induced fractionation, in Proceedings of the Soviet-American Conference on the Cosmochemistry of the Moon and Planets, edited by J. H. Pomeroy, NASA, in press, 1975.

Podosek, F. A., and J. C. Huneke, Argon in Apollo 15 green glass spherules (15426): ${ }^{10} \mathrm{Ar}-{ }^{30} \mathrm{Ar}$ age and trapped Ar., Earth Planet. Sci. Lett., 19, 413, 1973.

Price, P. B., I. Hutcheon, R. Cowsik, and D. J. Barber, Enhanced iron emission in solar flares, Phys. Rev. Lett., 26, 916, 1971.

Reed, G. W., and S. Jovanovic, Fluorine on lunar samples: Implications concerning fluoroapatite, Geochim. Cosmochim. Acta, 37. $1457-1462,1973$.

Rhodes, J. M., K. V. Rodgers, C. Shih, B. M. Bansal, I. E. Nyquist, H. Wiesmann, and N. J. Hubbard, The relationship between geology 
and soil chemistry at the Apollo 17 landing site, LSC5-2, 1097-1118, 1974.

Ringwood, A. E., and E. Essene, Petrogenesis of Apollo 11 basalts, internal constitution and origin of the moon, LSCI-I, 769-800, 1970.

Ringwood, A. E., and D. H. Green, Maria basalts and composition of lunar interior, Lunar Sci. 5, pp. 636-639, Lunar Sci. Inst., Houston, Tex., 1974.

Russ, G. P., III, Apollo 16 neutron stratigraphy, Earth Planet. Sci. Lett., 16, 275-289, 1973.

Russ, G. P., III, D. S. Burnett, and G. J. Wasserburg, Lunar neutron stratigraphy, Earth Planet. Sci. Lett., 15, 172-180, 1972.

Russell, C. T., J. Coleman, Jr., B. R. Lichtenstein, and G. Schubert, The permanent and induced magnetic dipole moment of the moon, LSC 5-3, 2747-2760, 1974.

Schneider, E., D. Storzer, J. B. Hartung, H. Fechtig, and W. Gentner, Microcraters on Apollo 15 and 16 samples and corresponding cosmic dust fluxes, LSC4-3, 3277-3290, 1973.

Schonfeld, E., $K$ and $U$ systematics and average concentrations on the moon, LSC5-2, 1135-1146, 1974.

Sharp, L. R., P. J. Coleman, Jr., B. R. Lichtenstein, C. T. Russell, and G. Schubert, Orbital mapping of the lunar magnetic field, Moon, 7, $322,1973$.

Silver, L. T., U-Th-Pb isotopes in some Tranquillity Base samples and implications for lunar history, LSCl-2, 1533-1574, 1970.

Silver, L. T., U-Th-Pb abundances and isotopic characteristics in some Apollo 14 rocks and an Apollo 15 soil, Lunar Sci. 3, Lunar Sci. Inst., Houston, Tex., 1972.

Silver, L. T., Patterns of U-Th-Pb distributions and isotope relations in Apollo 17 soils, Lunar Sci. 5, pp. 706-708, Lunar Sci. Inst., Houston, Tex., 1974.

Smith, J. W., I. R. Kaplan, and C. Petrowski, Carbon, nitrogen, sulfur, helium, and metallic iron in Apollo 15 drill stem fines, LSC4-2, 1651-1656, 1973.

Sonett, C. P., and D. S. Colburn, K. Schwartz, and K. Keil, The melting of asteroidal-sized bodies by unipolar dynamo induction from a primordial T Tauri sun, Astrophys. Space Sci., 7, 446-488, 1969.

Stephenson, A., D. W. Collison, and S. K. Runcorn, Lunar magnetic field palaeointensity determinations on Apollo 11, 16, and 17 rocks, LSC5-3, 2859-2872, 1974.

Stettler, A., P. Eberhardt, J. Geiss, N. Grögler, and P. Maurer, On the duration of lava flow activity in Mare Tranquillitatis, LSC5-2, $1557-1570,1974$.

Strangway, D. W., and H. A. Sharp, Lunar magnetism and an early cold moon, Nature, 249, 227, 1974.

Tatsumoto, M., C. E. Hedge, R. J. Knight, D. M. Unruh, and B. R. Doe, U-Th- $\mathrm{Pb}, \mathrm{Rb}-\mathrm{Sr}$, and $\mathrm{K}$ measurements on some Apollo 15 and Apollo 16 samples, in The Apollo 15 Lunar Samples, edited by J. Chamberlin and C. Watkins, pp. 391-395, Lunar Science Institute, Houston, Tex., 1972.

Tatsumoto, M., P. D. Nunes, R. J. Knight, C. E. Hedge, and D. M. Unruh, U-Th-Pb, Rb-Sr, and $\mathrm{K}$ measurements of two Apollo 17 samples (abstract), Eos Trans. AGU, 54, 614, 1973.

Taylor, H. P., Jr., and $\mathrm{S}$. Epstein, $\mathrm{O}^{18} / \mathrm{O}^{10}$ and $\mathrm{Si}^{80} / \mathrm{Si}^{28}$ studies of some Apollo 15, 16, and 17 samples, LSC4-2, 1657-1680, 1973.

Taylor, L. A., J. K. Mao, and P. M. Bell, 'Rust' in the Apollo 16 rocks, $L S C 4-1,829-840,1973$.

Taylor, L. A., H. K. Mao, and P. M. Bell, $\beta-\mathrm{FeOOH}$, akaganeite, in lunar rocks, LSC5-I, 743-748, 1974

Taylor, S. R., and P. Jakes, The geochemical evolution of the moon, LSC 5-2, 1287-1306, 1974.

Tera, F., O. Eugster, D. S. Burnett, and G. J. Wasserburg, Comparative study of $\mathrm{Li}, \mathrm{Na}, \mathrm{K}, \mathrm{Rb}, \mathrm{Cs}, \mathrm{Sr}$ and $\mathrm{Ba}$ abundances in achondrites and in Apollo 11 lunar samples, LSCI-2, 1647-1657, 1970.

Tera, F., D. A. Papanastassiou, and G. J. Wasserburg, The lunar time scale and a summary of isotopic evidence for a terminal lunar cataclysm, Lunar Sci. 5, pp. 792-794, Lunar Sci. Inst., Houston, Tex., 1974a.

Tera, F., D. A. Papanastassiou, and G. J. Wasserburg, Isotopic evidence for a terminal lunar cataclysm, Earth Planet. Sci. Lett., 22 $1-21,1974 b$.

Toksöz, N., and D. H. Johnston, The evolution of the moon and the terrestrial planets, in Proceedings of the Soviet-American Conference on the Cosmochemistry of the Moon and Planets, edited by J. H. Pomeroy, NASA, in press, 1975.

Toksöz, N., and S. C. Solomon, Thermal history and evolution of the moon, Moon, 7, 251-278, 1973.

Toksöz, N., A. M. Dainty, S. C. Solomon, and K. R. Anderson, Structure of the moon, Rev. Geophys. Space Phys., 12, 539-567, 1974.

Turkevich, A. L., The average chemical composition of the lunar surface, $L S C 4-2,1159-1168,1974$.

Turner, G., 39/40 argon dating of lunar rock samples, LSCI-2, $1665-1684,1970$

Turner, G., J. C. Huneke, F. A. Podosek, and G. J. Wasserburg, ${ }^{\text {t0 }}$ Ar${ }^{39} \mathrm{Ar}$ ages and cosmic ray exposure ages of Apollo 14 samples, Earth Planet. Sci. Lett., 12, 19-35, 1971.

Wänke, H., H. Baddenhausen, G. Dreibus, E. Jagoutz, H. Kruse, H. Palme, B. Spettel, and F. Teschke, Multielement analyses of Apollo 15,16 , and 17 samples and the bulk composition of the moon, LSC4-2, 1461-1482, 1973.

Wänke, H., H. Palme, H. Baddenhausen, G. Dreibus, E. Jagoutz, H Kruse, B. Spettel, F. Teschke, and R. Thacker, Chemistry of Apollo 16 and 17 samples: Bulk composition, late stage accumulation and early differentiation of the moon, LSC5-2, 1307-1337, 1974.

Warner, J. L., C. H. Simonds, and W. C. Phinney, Impact-induced fractionation in the lunar highlands. LSC5-1, 379-399, 1974.

Wasserburg, G. J., G. J. F. Macdonald, F. Hoyle, and W. A. Fowler, Relative contributions of uranium, thorium, and potassium to the heat production of the earth, Science, 143, 465-467, 1964.

Weill, D. F., G. A. McKay, S. J. Kridelbaugh, and M. Grutzeck, Modeling the evolution of $\mathrm{Sm}$ and Eu abundances during lunar igneous differentiation, LSC5-2, 1337-1352, 1974.

Wetherill, G. W., Solar system sources of meteorites and large meteoroids, Annu. Rev. Earth Planet. Sci., 2. 303-330, 1974.

Wlotzka, F., E. Jagoutz, B. Spettel, H. Baddenhausen, A. Balacescu and $H$. Wänke, On lunar metallic particles and their contribution to the trace element content of Apollo 14 and 15 soils, LSC3-1. 1077-1084, 1972.

Wlotzka, F., B. Spettel, and H. Wänke, On the composition of meta from Apollo 16 fines and the meteoritic component, LSC4-2, 1483-1492, 1973.

Wood, J. A., A survey of lunar rock types and comparison of the crusts of earth and moon, in Proceedings of the Soviet-American Conference on Cosmochemistry of the Moon and Planets, edited by J. H. Pomeroy, NASA, in press, 1975.

Wood, J. A., J. S. Dickey, Jr., U. B. Marvin, and B. N. Powell, Lunar anorthosites and a geophysical model of the moon, LSCI-I 965-989, 1970.

Woolum, D. S., D. S. Burnett, M. Furst, and J. Weiss, Measurement of the lunar neutron density profile, Moon, 12, 231-250, 1975

Yaniv, A., and D. Heymann, Atmospheric ${ }^{10} \mathrm{Ar}$ in lunar fines, LSC3-2, $1967-1980,1972$.

Yin, L. I., T. Tsang, and I. Adler, Electron spectroscopic studies related to solar-wind darkening of the lunar surface, Geophys. Res. Lett., 2, 33-36, 1975. 